\title{
Daño al proyecto de vida
}

Carlos Fernández Sessarego

\section{Introducción}

En el presente trabajo pretendemos, dentro de nuestras limitaciones, contribuir a precisar, como lo venimos haciendo desde hace casi dos décadas, los alcances conceptuales, a la altura de nuestro tiempo, del comúnmente denominado "daño moral». Hemos tenido presente para esta finalidad los amplios e importantes desarrollos logrados en tiempos recientes en torno al genérico y riquísimo concepto de «daño a la persona» o "daño subjetivo", tanto de parte de la doctrina como de la jurisprudencia comparada y de la más reciente codificación civil latinoamericana $^{1}$. No hemos tampoco perdido de vista, en función de la particular situación legislativa italiana, los desarrollos doctrinarios y jurisprudenciales del denominado «daño a la salud».

Es nuestro propósito, por su relevancia sistemática y conceptual, destacar desde nuestra perspectiva la nítida distinción entre la genérica noción de «daño a la persona» y el específico concepto de «daño moral», así como poner de manifiesto la relación de ambos conceptos con la novísima noción de "daño al proyecto de vida» y su vinculación con el «daño psíquico». Consideramos que tratándose de una materia novedosa y en constante evolución, como es la referente al daño a la persona en su más amplia acepción, es imprescindible deslindar y delinear los alcances y las relaciones existentes entre los anteriormente mencionados conceptos los que en la actualidad, según nuestro criterio, deben ser sometidos a un redimensionamiento conceptual para evitar confusiones, imprecisiones o innecesarias superposiciones ante los desarrollos alcanza-

1 Nos referimos al Código Civil peruano de 1984 el cual, en su artículo 1985, incorpora el deber de indemnizar, sin limitación alguna, el «daño a la persona». 
dos por la más avanzada doctrina y por la lúcida jurisprudencia en los días que corren.

Pero, de manera preferente, centramos nuestra atención y ensayamos algunas nuevas reflexiones sobre un tema que atrajo nuestro interés desde fines de la década de los años setenta, como es el por nosotros denominado "daño al proyecto de vida», el que constituye un importante componente del genérico "daño a la persona». Como el concepto de «daño al proyecto de vida» implica nada menos que una grave limitación al ejercicio de la libertad -en que consiste el ser humano- nos hemos visto obligados a una previa aproximación a la fascinante y decisiva disciplina de la Antropología Filosófica, la que nos suministra el correspondiente sustento teórico.

Recurrir a la Antropología Filosófica en busca de una imprescindible fundamentación a nuestras reflexiones no supone, por cierto, llevar a cabo una pura especulación sin fines prácticos. Por el contrario, efectuamos esta aproximación en cuanto somos de la opinión que, si no poseemos algunos previos y genéricos planteamientos en el marco de esta básica disciplina, podría no resultar fácil para los iniciados en la materia de este trabajo aprehender, en su profunda dimensión, la noción de «daño al proyecto de vida». Si no acudiéramos a la Antropología Filosófica con el propósito de poner en evidencia ciertos principios rectores que sirven de necesario e ineludible sustento a nuestra exposición, no sería improbable el que se pudiera pensar que el «daño al proyecto de vida» podría ser tan sólo una mera abstracción, un engañoso juego conceptual, una simple ilusión, algo irreal, en suma. $\mathrm{O}$, en el mejor de los casos, podríase recusar el concepto de "daño al proyecto de vida», que integra la genérica noción de «daño a la persona», para intentar reducirlo a los precisos alcances del «daño moral» o del «daño psíquico».

No es esta la oportunidad para enumerar los importantes trabajos publicados en estos últimos años no sólo en algunos países europeos sino también en ciertos países latinoamericanos, principalmente en la $\mathrm{Ar}$ gentina, sobre el daño a la persona y el daño moral. No obstante, reconforta observar como en nuestros días, a nivel jurídico, se ha revalorizado al ser humano y, por ende, se han fortalecido y afinado sus técnicas de tutela cuando las consecuencias del daño son de carácter no patrimonial o estrictamente personal. Es decir, no traducibles en dinero de modo directo e inmediato.

Este fenómeno fue advertido en 1992 por Clovis V. do Couto e Silva, ilustre civilista brasileño recientemente desaparecido. Al reconocer el aporte del Código civil peruano de 1984 y de la doctrina pertinente, tanto argentina como peruana expresó, refiriéndose a la pluralidad y cali- 
dad de los trabajos aparecidos en los últimos tiempos, que ellos conforman «un micro sistema avanzado, a la altura de los mejores del mundo jurídico en similar estadio de evolución jurídica». Y advirtió el que en muchos de dichos trabajos se recoge el nuevo concepto de «daño a la persona" en sustitución del de daño "moral». Ello, agregó, permite apreciar, "con alborozo y satisfacción profundas", que "constituye la mejor prueba de la acogida favorable que el Código peruano tuvo, al incorporar la nueva categoría $»^{2}$. El eminente jurista brasileño aludía a la inclusión del daño a la persona, sin limitación alguna, en el artículo 1985 del Código Civil peruano de 1984, hecho que ha merecido numerosos comentarios en la ultima década.

Para el esclarecimiento de la temática bajo análisis consideramos que es ilustrativo tener en cuenta la nueva sistematización de los daños que hemos propuesto ${ }^{3}$ a fin de diferenciar los daños según la naturaleza del objeto dañado, de una parte y, de la otra, de acuerdo a las diversas consecuencias derivadas de la lesión inferida al objeto. Estimamos que esta sistematización, a la que hemos hecho referencia en trabajos anteriores, contribuye, a nuestro entender, en gran medida a distinguir los alcances y las implicancias entre los conceptos de «daño a la persona», «daño moral», «daño psíquico» y «daño al proyecto de vida». Ello se pondrá de manifiesto en el curso de este trabajo.

\section{El proyecto de vida}

\section{a. Libertad, temporalidad y proyecto de vida}

Le debemos a Martín Heidegger el que, en su profunda obra El ser y el tiempo, haya presentado al ser humano como un ser temporal. Para el fi-

\footnotetext{
2 Las expresiones de Clovis V. do Couto e Silva están recogidas en el trabajo de Jorge Mosset Iturraspe, titulado "El daño a la persona en el Código Civil peruano", presentado al Congreso Internacional conmemorando los diez primeros años de vigencia de dicho Código Civil, reunido en Lima en setiembre de 1994, publicado en el volumen Los diez años del Código civil peruano: balance y perspectiva, T.I, Lima, Universidad de Lima, 1995, p. 213.

3 El intento de efectuar una sistematización de los daños a fin de lograr precisiones en cuanto a la comprensión del concepto "daño a la persona" aparece en el trabajo del autor "Hacia una nueva sistematización del daño a la persona" publicado en Estudios en honor de Pedro J. Frias, Academia Nacional de Derecho y Ciencias Sociales, Córdoba, 1994, T.II, p. 1087 y ss. También ha sido publicado en Cuadernos de Derecho, No. 3, Universidad de Lima, Lima, 1993, p. 28 y ss. y en Ponencias I, Congreso Nacional de De-
} 
lósofo alemán el tiempo es lo que permite a que cada uno (el «ser ahí») comprenda e interprete, en general, lo que se menta como «ser». El análisis de la historicidad del «ser-ahí» trata de mostrar, según Heidegger, que este ente no es temporal por estar «dentro de la historia», sino que, a la inversa, sólo existe y puede existir históricamente "por ser temporal en el fondo de su ser»" ${ }^{4}$. El tiempo se constituye, de este modo y según expresión de Heidegger, en «el genuino horizonte de toda comprensión e interpretación del ser». Es decir, que el tiempo es el horizonte para el recto planteo del ser. O, como señala Ceñal, «el tiempo hecho existencia, es la raíz de todo saber y de toda ciencia» ${ }^{5}$.

Sartre coincide con dichas apreciaciones cuando sostiene que el ser humano es un existente cuya existencia individual y única se temporaliza como libertad». La libertad se despliega en el tiempo, por lo que podemos referirnos a la existencia como el tiempo de nuestra libertad y, a la vida, como la vida de nuestra libertad.

El ser humano es tiempo. Constituye un proceso temporal, abierto, donde el pasado condiciona el presente y, desde éste, se proyecta el futuro. El futuro está, por ende, dado en el presente en forma de proyecto. Si el ser humano es temporal es, también y por consiguiente, un ser histórico. La libertad en el tiempo, la vida temporal de la libertad, hacen posible que cada ser humano se proyecte, se realice, despliegue su personalidad, tenga una biografia y una identidad.

Se suele decir, en frase de corte materialista, que "el tiempo es oro". Ella, sin embargo, entraña un profundo error en lo que concierne a la percepción del ser humano así como en cuanto a las jerarquías axiológicas prevalecientes en el mundo en que vivimos. $Y$ es que no hay nada más importante para el ser humano que el tiempo de la libertad. Por ello, lo correcto sería afirmar, por el contrario, que «el oro es tiempo».

Si el ser humano es tiempo, su ser está por hacerse a partir del don de la vida. El ser humano no es una cosa, hecha, terminada, maciza, sino que, por el contrario, es lábil y fluido, desplegado en el tiempo, haciéndose permanentemente con los «otros» y con las «cosas» del mundo. La existencia es un hacerse a sí mismo dentro de la temporali-

recbo Civil y Comercial, Universidad Nacional Mayor de San Marcos, Lima, 1994, p. 23 y ss.

4 Henecgier, Martín, El ser y el tiempo, Fondo de Cultura Económica, Traducción de José Gaos, México, 1951 , p. 433.

CENAL, Ramón, en La filosofía de Martín Heidegger de A. de Waehlens, nota preliminar, p. XVI. 
dad. Por ello, Jaspers puede afirmar que «el ser sólo se nos abre en el tiempo" ${ }^{6}$.

El ser humano, para realizarse en el tiempo en tanto ser libre, debe proyectar su vida. La vida resulta, así, un proceso continuado de haceres según sucesivos proyectos. El proyecto tiene como condición la temporalidad. En el presente decidimos lo que proyectamos ser en el instante inmediato, en el futuro, condicionados por el pasado.

Para proyectarnos al futuro contamos con el pasado que, como apunta Zubiri, sobrevive «bajo la forma de estar posibilitando el presente» ${ }^{7}$. Somos el pasado, "porque somos el conjunto de posibilidades de ser que nos otorgó al pasar de la realidad a la no realidad $»^{8}$. El filósofo hispano desarrolla su pensamiento al expresar que «en cuanto realidad, el pasado se pierde inexorablemente». Pero, sin embargo, no "se reduce a la nada». El pasado "se desrealiza, y el precipitado de este fenómeno es la posibilidad que nos otorga» Por ello, puede afirmar que "el pasado se conserva y se pierde» ${ }^{9}$. Nuestras experiencias, nuestras pretéritas vivencias, posibilitan nuestra decisión de ser.

Pero, así como el pasado está dado en el presente, el futuro también lo está, porque siendo lo que aún no es, sus posibilidades están ya dadas en el presente. Para Zubiri, «sólo es futuro aquello que aún no es, pero para cuya realidad están ya actualmente dadas en un presente todas sus posibilidades" ${ }^{10}$. Sartre es radical al considerar que sea el futuro. Ello, en la medida que, para él, el ser del hombre está en el futuro. El «ser para sí», según el filósofo galo, está fuera del hombre en cuanto se manifiesta en el futuro a través del proyecto. El ser del hombre es hacer proyectos. Y, hacer proyectos, es poner el ser en el futuro. Es esta, para Sartre, la decisiva trascendencia existencial del proyecto.

Como el ser es libertad en el tiempo, o temporalización de la libertad, la vida humana es una sucesión de quehaceres, un constante dinamismo, un tener que decidir lo que se va a ser. Como seres libres y temporales estamos condenados a proyectar. La vida es un constante proyectar. Algunos de nuestros proyectos se cumplen, otros, en cambio, se frustran.

6 JAspers, Karl, La fo filosífica, Editorial Losada, Buenos Aires, segunda edición, 1968 , p. 129.

7 Zubiri, Xavier, Naturaleza, Historia, Dios, Editorial Poblet, Buenos Aires, 1948 , p. 347.

\& Zubiri, Xavier, Ibidem, p. 350.

Zuisri, Xavier, Ibidem, pp. 346 y 347.

Zußır, Xavier, Ibidem, p. 348. 
El proyecto, por consiguiente, se sustenta en la libertad y en la temporalidad del ser humano. Si éste no fuera un ser libre y temporal, carecería de sentido referirse al "proyecto de vida". Pero, al mismo tiempo, por ser libre y temporal debe, necesariamente, proyectarse. Se vive proyectando, se proyecta viviendo la vida temporal de la libertad. Es imposible para el ser humano, en cuanto ser libre y temporal, dejar de proyectar.

El proyectar es la manera de ser del ser humano en cuanto libre y temporal.

\section{b. Proyecto y valoración}

Para proyectar se debe decidir. Decidir supone elegir un determinado proyecto, descartando al mismo tiempo otros proyectos alternativos dentro del inmenso abanico de posibilidades que se le presentan al ser hamano en un momento dado de su historia personal. Decidir es, por ello, escoger o elegir entre diversas posibilidades para formular «un proyecto de vida»: lo que se decide ser en el futuro. Sólo puede elegir quien es ontológicamente libre.

Pero, para elegir, se requiere preferir «esto" sobre «aquello». Toda decisión libre significa, por ello, una valoración. Decidir es valorar para optar por éste u otro proyecto alternativo. De ahí que el ser humano es estimativo, en cuanto tiene la potencialidad, inherente a su ser, de vivenciar valores. La vida es así, una sucesión de valoraciones. El estimar, el valorar, es una irrenunciable instancia de la vida humana. El ser humano es, como está dicho, un ser estimativo, lo que le viene de su condición de ser libre.

El verdadero lugar de los valores, como apunta Mounier en acertada metáfora, es el «corazón vivo del hombre». Los valores se revelan al ser humano en las profundidades de la libertad, madurando con el acto que los elige. El ser humano es, como está dicho, un ser estimativo, es decir, un ser estructuralmente dotado para vivenciar, para sensibilizar valores. El ser humano no podría vivir sin los valores, con los que otorga un sentido a su existir. Como lo dice el propio Mounier, «las personas sin los valores no existirían plenamente, pero los valores no existen para nosotros sino por el fiat veritas tua que les dicen las personas» ${ }^{11}$.

\footnotetext{
1 Mounitr, Emmanuel, El personalismo, Editorial Eudeba, Buenos Aires, 1962 , p. 42 .
} 
El ser humano para proyectar, como está dicho, vivencia valores, lo que le permite escoger entre una infinidad de posibilidades aquella que decide ser en el futuro. Puede privilegiar el valor de la virtud o del bien, el de la justicia, el de la belleza, el de la utilidad, el de la solidaridad, el del amor o cualquiera otro dentro de la inmensa gama bipolar que constituye lo que se conoce como "la jerarquía valorativa». La preeminencia que adquiera alguno de ellos en la vida del ser humano le otorga un sentido, le proporciona un rumbo, signa su entero existir. Los valores, por ello, se dan «en» y «para» la vida humana.

El proyecto se decide, se elige libremente en el horizonte del tiempo. Es en la instancia insecuestrable del ser donde cualquier proyecto es posible. El ser humano decide valiéndose de su libertad, de su imaginación, de su vocación estimativa y de los estímulos que le ofrece su «circunstancia», en expresión cara a Ortega y Gasset. Es decir, del mundo en el cual está instalado.

Cada ser humano debería, en el instante de proyectar, tener conciencia de sus reales posibilidades, tanto de aquellas que le ofrece su mundo psicosomático como de las que se hallan situadas en el mundo exterior. Ello, para los fines de la realización o de la frustración del «proyecto de vida", es de suma importancia. El hombre debería elegir proyectos viables, capaces de ser cumplidos en función de sus propias potencialidades y de las que le ofrece su "circunstancia".

Por la valoración, a través del proyecto, el ser humano se propone fines, los que se realizan utilizando nuestra envoltura psicosomática y los elementos que nos facilita el mundo exterior. Los fines, en palabras de Sartre, "son la proyección temporalizante de nuestra libertad". La libertad crea, escoge los fines, «y, por su elección misma, les confiero:una existencia trascendente como límite externo de sus proyectos» ${ }^{\prime 2}$.

El ser humano, para realizar un proyecto de vida al par que su posibilidad de vivenciar valores, cuenta con sus propias potencialidades psicosomáticas, con los otros y con las cosas del mundo. Todo ello le ofrece un vasto horizonte de posibilidades. Para realizar un proyecto se vale, desde su yo, de su cuerpo y de su psique, de los otros, de las cosas, condicionado por su pasado. Todo ello le sirve como estímulos y como posibilidades para proyectar su vida.

La realización fenoménica del proyecto está condicionada ya sea por las posibilidades como por las resistencias que le ofrecen tanto su mun-

12. Sartri, Jean Paul, El ser y la nada, Editorial Ibero Americana, Buenos Aires, 1948, Tomo III, P. 24. 
do interior, su unidad psicosomática, como por aquellas del mundo exterior. No sólo el cuerpo o la psique pueden frustrar el proyecto de vida sino también los obstáculos que le ofrecen las cosas y, por cierto, la acción de los demás en el seno de la sociedad.

No se puede asegurar que la decisión libre se cumpla. El que el ser humano sea libre y pueda, por consiguiente, decidir, valorar y proyectar no significa necesariamente que, en el ejercicio de la libertad, en la fenomenalización de esa decisión libre, el proyecto se realice, se concrete, se convierta en acto de conducta. Como bien señala Kierkegaard, la libertad «no es alcanzar esto y aquello en el mundo, de llegar a ser rey o emperador y a vocero de la actualidad, sino la libertad de tener en sí mismo la conciencia de que, es hoy libertad $\gg^{13}$. La libertad que somos es, pues, independiente de la realización o no del proyecto. Los proyectos se cumplen o se frustran. La realización o la frustración de un proyecto no afecta la libertad en cuanto ser del hombre. Como Sartre lo precisa, «ser libre no significa obtener lo que se quiere sino determinarse a querer (en sentido amplio de elegir)». De ahí que se pueda concluir afirmando coherentemente "que el éxito no interesa en ningún modo a la libertad» ${ }^{14}$. Es decir, a la libertad que cada uno es.

Por ser la existencia coexistencia, el proyecto ha de cumplirse necesariamente "con" los demás seres humanos, valiéndose de las cosas. Esta particular situación posibilita que el proyecto se cumpla, total o parcialmente, o que simplemente se frustre. La decisión fue libremente adoptada, pero su cumplimiento depende del mundo, tanto interior como exterior. Por lo demás, en cuanto el ser humano es libre, resulta un ser impredecible. Puede esperarse de él, en consecuencia, la formulación de cualquier proyecto.

Es oportuno señalar que se suele confundir la libertad, que es el ser mismo del hombre, con la voluntad, que es un aspecto de la psique, sin percatarse que ésta se halla, como la unidad psicosomática en su conjunto, al servicio del yo, de la decisión libre. La envoltura psicosomática es un medio del cual se vale la libertad para su realización como proyecto. Por ello es posible referirse a «mi» cuerpo, a «mi» voluntad.

Sartre ha descrito certeramente la relación entre la «libertad» y la «voluntad». Al referirse a la primera apunta que «el planteamiento de mis fines últimos es lo que caracteriza a mi ser y lo que se identifica con la aparición original de la libertad que es mía». Es así que la libertad re-

13 Kierkiciand), Sören, El concepto de la angustia, Editorial Espasa Calpe, Buenos Aires, $2^{\circ}$ edición, 1943, p. 118.

14 SARTrk, Jean Paul, El ser y la nada, T. III, p. 82. 
sulta ser el fundamento de los fines que el ser humano decide realizar "sea por la voluntad, sea por esfuerzos pasionales». Sartre señala que "las voliciones son, por el contrario, como las pasiones, ciertas actitudes subjetivas por las cuales tratamos de alcanzar los fines propuestos por la libertad originaria». La libertad es, así, "un fundamento rigurosamente contemporáneo de la voluntad.(...) que manifiesta a su manera» $»^{15}$.

La voluntad, según Sartre, «se presenta como decisión reflexionada con relación a ciertos fines". Pero, afirma a continuación, que esos fines no los crea la voluntad. Esta sólo «decreta que la persecución de esos fines sea reflexiva y deliberada» ${ }^{16}$.

\section{Alcances del concepto «Daño a la persona»}

\section{a. ¿ Daño a la persona o daño subjetivo ?}

En la última década se ha incrementado notablemente la literatura sobre el ser humano en cuanto sujeto de derecho y, más precisamente, sobre el denominado "daño a la persona». Ello delata la influencia del personalismo o humanismo en el pensamiento jurídico, lo que proviene de las formulaciones o propuestas de la filosofia de la existencia. Personalmente, el tema nos sedujo desde que tomamos contacto con él a finales de la década de los setenta, lo que nos permitió introducir en el Art. 1985 del Código Civil peruano de 1984, después de intensos y prolongados debates, el deber de indemnizar el daño a la persona, considerado en sí mismo, al lado del daño emergente, del lucro cesante y del daño moral en sentido estricto.

El tema fue tratado por nosotros en 1984, es decir en el mismo año en el que se promulgaba, un 24 de julio, el Código Civil peruano. Fue así que le dedicamos al asunto del daño a la persona un ensayo que apareció en el Libro Homenaje a José León Barandiarán bajo el título de El daño a la persona en el Código Civil de $1984^{17}$. En este ensayo se deslindaban las nociones de «daño a la persona» y «daño moral» y se indicaba, al mismo tiempo y como una intuición central, que «el más grave

\footnotetext{
15 SarTre, Jean Paul, Ibidem, T. III, p. 25.

in Sartre, Jean Paul, Ibidem, p. 24.

17 Fernández Sissartio, Carlos, "El daño a la persona en el Código Civil de 1984", en Libro Homenaje a Josí León Barandiarán. Edit. Cuzco, Lima, 1985, p. 163 y ss. y en Nuevas tendencias en el derecho de las personas, Universidad de Lima, Lima, 1990, p. 261 y ss.
} 
daño que se puede causar a la persona es aquel que repercute de modo radical en su proyecto de vida, es decir, aquel acto que impide que el ser humano se realice existencialmente de conformidad con dicho proyecto libremente escogido, atendiendo a una personal vocación ${ }^{18}$. Esta fue la primera oportunidad en que hicimos referencia escrita a esta radical modalidad de daño al proyecto de vida, idea que había madurado en nosotros a través del tiempo, a partir de una más honda reflexión sobre la estructura misma del ser humano, artífice y protagonista del Derecho.

Dicha inquietud nos movió también a presentar una ponencia sobre el mismo tema incluyendo nuevas reflexiones, en el Congreso Internacional «El Código Civil peruano y el sistema jurídico latinoamericano», que organizara en 1985 la Universidad de Lima ${ }^{19}$. Desde aquel entonces la idea encontró su propio camino. Por nuestra parte, hemos continuado en lo posible, muy atentos, estudiando y enriqueciéndonos con la valiosa y cada vez más numerosa producción sobre este capital asunto, lo que nos ha incentivado a dedicarle nuestro máximo interés. Nos reconforta advertir como el daño a la persona, en todas sus complejas y ricas modalidades, ha logrado ocupar en la actualidad la preferente atención de los juristas.

Es conveniente aclarar que el llamado daño a la persona incluye también los perjuicios que se puedan causar al concebido o persona por nacer. Fue esta la atendible razón por la que Carlos Cárdenas Quirós propusiera que el daño a la persona debería denominarse "daño subjetivo", a fin de que no cupiera duda alguna que también se incluía dentro del referido concepto al nasciturus ${ }^{20}$.

No obstante compartir a plenitud los propósitos antes enunciados, continuaremos utilizando, al menos por el momento, la expresión «daño a la persona», como equivalente de "daño subjetivo». Ello, como tributo a una demasiada reciente y naciente concepción, en trance de consolidarse, y con el objeto de evitar confusiones en un asunto que, por lo general, no termina de aclararse a nivel de la doctrina donde se sigue superponiendo o confundiendo por ejemplo, «daño a la persona» con «daño «moral».

18 Frirnández Srissartio, Carlos, "El daño a la persona en el Código Civil de 1984", en Libro Homenaje a José Leín Barandiarán, p. 202.

19 Frrnánitz Sessarticio, Carlos, "El daño a la persona en el Código Civil peruano de 1984 y el Código Civil italiano de 1942" en El Código Civil peruano y el sistema jurídico latinoamericano, Edit. Cuzco, Lima, 1986, pp. 251 y ss.

20 CÁrdenas Quirós, Carlos, "Apuntes sobre el denominado daño a la persona" en Revista de Derecho y Ciencias Políticas, Facultad de Derecho de la Universidad de San Marcos, vol. 4, anos 1987-1989, Lima, 1989. 
Aunque no es nuestro propósito referirnos en esta oportunidad a las modalidades de protección de la persona frente a los daños que se le pueden inferir ${ }^{21}$, no es posible dejar de aludir, aunque fuere esquemáticamente, al hecho de que la tutela de la persona, aparte de ser preventiva, unitaria e integral-como corresponde a su naturaleza-, no sólo se reduce a la afectación de los aspectos de la vida humana tutelados específicamente por los derechos subjetivos perfectos, alojados en las normas del ordenamiento jurídico positivo, sino que también incluye a los intereses existenciales aún no recogidos por dicho ordenamiento. Es decir, lo que designamos como derechos subjetivos imperfectos.

Es por ello, como es sabido, que el ser humano está protegido por cláusulas generales o abiertas o en blanco, que incluyen, precisamente, aquellos intereses existenciales o derechos subjetivos imperfectos que no están expresamente tutelados a través de una norma del ordenamiento jurídico. A este respecto podemos citar, a título de ejemplo, el artículo $3^{\circ}$ de la Constitución Política del Perú de $1993^{22}$. El artículo $5^{\circ}$ del Código Civil peruano de 1984 concuerda con la amplitud de esta cláusula general de protección del ser humano ${ }^{23}$.

\section{b. ¿ Daño a la persona o daño moral ?}

Debemos aclarar que es importante remarcar, tal como lo hemos venido sosteniendo por más de una década y como también ocurre en la obra de algunos autores, el distingo existente entre la tradicional expresión de «daño moral» y la contemporánea de «daño a la persona». De su simple enunciado, aplicando una lógica más que elemental, se deduce que el "daño moral» (pretium doloris) no es otra cosa que una modalidad del daño a la persona y, por consiguiente, es una especie de concepto comprensivo, es decir, de una noción genérica que lo engloba y subsume. Y

21 El tema ha sido tratado en el libro del autor Protección juridica de la persona, Universidad de Lima, Lima, 1992.

22 El siguiente es el texto del Art. $3^{\circ}$ de la Constitución peruana de 1993: "La enumeración de los derechos establecidos en este capítulo no excluye los demás que la Constitución garantiza, ni otros de naturaleza análoga o que se fundan en la dignidad del hombre, o en los principios de soberanía del pueblo, del Estado democrático de derecho y de la forma republicana de gobiernom.

23. El texto del Art. $5^{2}$ del Código Civil peruano de 1984 es el siguiente: "El derecho a la vida, a la integridad física, a la libertad, al honor y demás derechos inherentes a la persona humana son irrenunciables y no pueden ser objeto de cesión. Su ejercicio no puede sufrir limitación voluntaria, salvo lo dispuesto en el artículo $6^{\circ}$ \%. 
ésta, obviamente, es la de daño a la persona. Lo «moral», quien lo duda, es solo un «aspecto» de la compleja estructura del ser humano.

En 1985 sosteníamos que «la restringida acepción de daño moral a que nos hemos referido, no coincide, por cierto, con el concepto de daño a la persona que hemos esbozado. El daño a la persona tiene alcances muchos más amplios y profundos que un sentimiento, un dolor o sufrimiento" $Y$ agregábamos que el daño a la persona «significa el agravio o lesión a un derecho, a un bien o un interés de la persona en cuanto tal", comprendiéndose dentro de él "hasta la frustración del proyecto existencial de la persona humana». Todo ello, decíamos, "es más complejo que el sufrimiento o el dolor ${ }^{24}$.

Hoy más que nunca, al encontrarse en juego dos conceptos, que para algunos autores podrían tener la misma significación -situación que negamos pero que se presenta en la literatura jurídica-, tenemos el convencimiento de la necesidad de que cada autor, que trate o roce este tema, debería esclarecer su posición en torno a los alcances y relación que dentro de su personal concepción otorga a los conceptos de «daño a la persona» y de "daño moral».

La tradicional concepción del daño moral se centra en el daño ocasionado al ámbito afectivo o sentimental de la persona, lo que trae como consecuencia, sufrimiento, dolor, perturbación espiritual. Decimos que es un daño a determinado "aspecto" de la persona, al igual que una multiplicidad de otros daños lesionan otros tantos aspectos del complejo $y$, a la vez, unitario ser humano. Se trata en este específico caso de la lesión a una modalidad del género "daño a la persona». Por esta razón somos de la opinión que debe incluirse la restringida noción de daño moral dentro de aquella otra, genérica y comprensiva, de daño a la persona. $Y$ es que el daño moral no es otra cosa, como está dicho, que un daño específico que compromete básicamente la esfera afectiva o sentimental de la persona, ocasionándole una perturbación, un dolor, un sufrimiento que carece de un sustento patológico. No tiene sentido, por lo tanto y en nuestro concepto, seguir otorgando autonomía jurídica a una voz que se encuentra conceptualmente subsumida dentro de otra que es genérica y comprensiva.

La ciencia progresa, nos proporciona nuevas informaciones, inéditas revelaciones. Los juristas debemos estar atentos a estos mensajes de los tiempos, que provienen de la incontrolable realidad de la vida. No pode-

24 Frrnández Stssartio, Carlos, "El daño a la persona en el Código Civil peruano de 1984", en Libro Homenaje a José León Barandiarán, p. 214. 
mos seguir aferrados a viejos esquemas, que la vida se encarga de superar o de transformar. El «descubrimiento» del concepto de daño a la persona no obedece a un capricho, a un afán de novedad, a una vana pretensión académica. Responde, simplemente, a la realidad y se genera, como se ha puesto de manifiesto, cuando los juristas contamos con una mayor información sobre la estructura y comportamiento del ser humano a partir de los hallazgos y de los aportes de la filosofía de la existencia. Cuando se llega a comprender que el ser humano no es sólo y únicamente, como pretendía Boecio en el siglo VI de nuestra era, un ser «racional», sino también, y fundamentalmente, un ser libre, temporal y coexistencial. Es a raíz de esta nueva visión del ser humano que los juristas nos vemos obligados, con honesta humildad científica, a revisar y actualizar nuestras convicciones, alejados de toda soberbia o vanidad, a la luz de las nuevas percepciones sobre el creador, protagonista y destinatario del derecho: el ser humano.

Milmaiene sostiene una posición particular en lo atinente al distingo que cabe formular, por ejemplo, entre daño moral y daño psíquico. Sostiene que el daño moral supone «un sufrimiento subjetivo que no necesariamente se expresa a través de síntomas o de cualquier otra alteración psicopatológica». Es decir, que el daño moral no acarrea consecuencias psicopatológicas sino sentimentales. De ahí que, en opinión del autor, «el daño moral configura una categoría ajena a los métodos y posibilidades de la psicología, debiéndosele inscribir en el amplio campo de una teoría de los valores" 25 .

Debemos recordar que antes que los juristas advirtieran con claridad los genéricos alcances del daño a la persona -es decir, al considerar al ser humano en su inescindible unidad-algunos jueces, en las ultimas décadas, se mostraban proclives a reparar dispersas y específicas lesiones al ser humano, otorgándole autonomía a una inconexa diversidad de daños referidos a determinados y concretos aspectos de la persona. Nos referimos a la multiplicidad de denominaciones o de etiquetas, que inicialmente a nivel jurisprudencial y luego doctrinario, reclamaban autonomía conceptual para cada una de ellas, sin percibir la unidad en que consiste el ser humano. Así, se aludía, entre otras, a las voces de daño a la vida de relación, de daño estético, de daño psíquico, de daño sexual, de daño por muerte del concubino. No se tomaba conciencia de la esencial conexión existente entre ellas ni el consiguiente fundamento

25 Milmalt:Nt, José, "El daño psíquico", en Los nuepos daños, Hammurabi, Buenos Aires, 1995, p. 75. 
común, que no es otro que el ser humano en sí mismo, como inescindible unidad.

Es del caso advertir que el continuar otorgando autonomía conceptual al daño «moral» supondría y, a la vez, justificaría, el brindarle igual rango a cada uno de los múltiples daños que, en número cada vez mayor, lesionan específicos aspectos o fragmentos del ser humano. Por el contrario, dada la unidad del ser humano, todos los daños que se le ocasionen deberían sistemáticamente incorporarse, para el efecto de su reparación, dentro de la genérica noción de daño a la persona. Así lo exige la naturaleza misma del ser humano y el único y común fundamento que los conecta esencialmente, como es el ser humano en sí mismo.

Con el correr de los años un importante sector de la doctrina, al comprender los fundamentos expuestos en precedencia, ha incorporado sistemáticamente todas aquellas voces y cualquier otra que signifique lesión a un determinado aspecto de la unidad psicosomática en que consiste la persona, dentro de la genérica y expresiva voz de «daño a la persona». Si esto es así, nos preguntamos ¿qué razón habría para que un daño a la esfera afectiva o sentimental del ser humano, que genera dolor o sufrimiento, no se incorpore para un tratamiento sistemático, como cualquiera de aquellas otras voces, a la genérica noción de daño a la persona?. ¿Por qué insistir en una inexistente autonomía desmentida por la realidad misma del ser humano?. Tal vez la respuesta la tenga Jorge Mosset Iturraspe, a cuyo lúcido pensamiento dedicamos los siguientes párrafos.

Debemos señalar, con satisfacción, que la posición que sustentamos la compartimos, hasta el momento, con ilustres juristas de otras latitudes como es el caso, entre otros, del citado profesor Jorge Mosset Iturraspe. El maestro argentino, en un reciente Congreso Internacional sobre «Los diez años del Código Civil peruano: balance y perspectiva», organizado por la Universidad de Lima en setiembre de 1994, sostuvo, en una brillante ponencia, que desde hace algunos años se bregaba en la Argentina por incluir el restringido concepto de daño moral dentro del de daño a la persona ${ }^{26}$.

Al referirse al aporte del Código Civil peruano de 1984 de haber incorporado en su artículo 1985, sin limitaciones, el genérico concepto de "daño a la persona», Mosset Iturraspe expresa que "la sanción del Código Civil del Perú de 1984, en su artículo 1985, al separar el daño a la

26 Mosset Iturraspe, Jorge, "El daño a la persona en el Código Civil peruano", en Los diez años del Código civil, Universidad de Lima, Lima, Tomo primero, pp. 211 y ss. 
persona del daño moral, logró un resultado sorprendente; permitió que el velo que oscurecía nuestra visión cayera; que los prejuicios o preconceptos que nos ataban a una calificación décimonónica fueran dejados de lado; posibilitó el paso del conceptualismo al realismo, en una materia tan humana y sensibilizada». ${ }^{27}$

Consideramos de gran importancia e interés el deslinde que formula Mosset Iturraspe entre conceptualismo y realidad. Y es que muchos de los juristas, bajo la secular influencia de una visión formalista del Derecho, nos hemos habituado a "construir» instituciones, olvidándonos, cada cierto tiempo, de confrontarlas con la realidad de la vida a la cual se refieren como simples estructuras conceptuales. Nos cuesta trabajo dejar de lado, cuando ello es indispensable, las formas para acercarnos a la vida, a la fuente misma del Derecho. Cruza por nuestra mente, en este instante, una frase de Husserl que nos marcó desde jóvenes y que es algo así como un "grito de guerra" contra todo exacerbado conceptualismo alejado de la realidad. Husserl, al tratar de descubrir, de develar el ser mismo (noumeno), nos aconsejaba poner entre paréntesis todo aquello que perturbaba nuestra visión, que nos desviaba de la recta y directa vía epistemológica para acceder al ser mismo. Por ello su drástico consejo, que suena a mandato, fue: «a las cosas mismas». Es decir, la necesidad de librarnos de la maraña conceptual, que a menudo nos ata, constriñe y confunde, para enfrentar la realidad tal como se nos ofrece. Por ello, a la manera de Husserl, podríamos proclamar, tratándose del Derecho, este úkase: «a la experiencia misma». Que equivaldría, en el caso que nos ocupa, a despojarnos, como quiere Mosset Iturraspe, de preconceptos, de prejuicios, observar la realidad, tal como se nos presenta, para confirmar si nuestra antigua «construcción» conceptual sigue adecuándose al mundo que vivimos o, por el contrario, debemos hacer reajustes o remodelaciones $o$, simplemente, reconstrucciones conceptuales a la luz de la experiencia.

En su citada ponencia Mosset Iturraspe, al considerar que la noción de daño moral integra la más amplia de daño a la persona, establecía con precisión los alcances conceptuales del denominado daño "moral». En este sentido sostuvo que «la reparación del dolor es ahora un capítulo, pero no toda la materia. Con dolor o sin él, se debe respetar la intimidad, la vida de relación, los proyectos, la salud, entendida de una manera plena e integral». Y añadía, sintetizando su pensamiento, que «el 
centro de la cuestión no es más el dolor, es el hombre, la persona humana, su dignidad, sus virtualidades, sus apetencias ${ }^{28}$.

Mosset Iturraspe sostenía, en el mencionado Congreso Internacional de setiembre de 1994, que algunos autores se resisten a eliminar de los códigos civiles la específica categoría de daño moral por razones vinculadas «con su prestigio, con su abolengo, con su tradición jurídica». Distanciándose de esta posición, el maestro argentino sostuvo en aquella ocasión que «hay que dejar de lado la categoría del daño moral, hay que omitirla de los códigos para sustituirla por la de daño a la persona». Y ello, expresaba, porque «el daño moral, en primer lugar, es absolutamente impreciso desde sus orígenes, desde su denominación, desde su comprensión». Y, al preguntarse por lo que significaba el "daño moral» apuntaba, con realismo, que este no era otra cosa que un simple daño «jurídico», un daño a la vida de relación que otro me causa. Sostenía, con total lucidez, que el denominado daño moral "no es un problema de mi eticidad resentida, de mi moral que me reprochan. No es moral, es jurídico. ¡Y se llama moral! » ${ }^{29}$.

¿No son acaso absolutamente ciertas las atinadas observaciones de Mosset Iturraspe sobre el daño «moral»? Estimamos que ellas son totalmente esclarecedoras y si admitiéramos, como sería el caso, sus fundadas convicciones empezaríamos a dejar de lado, al referirnos al tratamiento jurídico del daño a la persona, la voz «moral» que confunde y enturbia el pulcro enfoque jurídico de la cuestión. Nos preguntamos, ¿qué razón existe para no realizar una operación inversa a la que efectúa un sector de la doctrina que es la de pretender subsumir lo genérico en lo específico, que otra cosa no significa la de reducir todos los múltiples daños a la persona a la específica voz de daño moral? ¿Lo lógico y sistemático no sería acaso, por el contrario, incorporar todos los daños al ser humano, incluyendo el moral, a la genérica voz de daño a la persona o daño subjetivo?

En conclusión, compartimos a plenitud el pensamiento de Mosset Iturraspe cuando sostiene que la expresión daño moral «es una antigualla, el daño moral es un resabio de otros tiempos que ha permanecido por nuestras debilidades, por nuestras torpezas, por nuestro aferrarnos a las tradiciones jurídicas ${ }^{30}$. Obviamente, en este caso, el maestro argentino se refiere a aquellas tradiciones -como la que comenta-

\footnotetext{
28 Mossht Iturrasin, Jorge, ibidem. p. 213.

29 Mosslit Iturkaspe, Jorge, "Más allá del daño moral el daño a la persona" en Diez años del Código Civil peruano, Tomo II, pp. 406 y 407.

30 Mosset Iturkasph, Jorge, ibidem. p. 408.
} 
mos- que han perdido vigencia pues han surgido nuevas formas o modalidades de conductas humanas intersubjetivas diversas, sustitutorias o de signo contrario.

\section{c. Daño a la persona y daño moral en el Código Civil perua- no de 1984}

Mosset Iturraspe reprocha, con acierto y en su momento, que se hubiera incluido en el Art. 1985 del Código Civil peruano de 1984 la expresión de daño moral simultáneamente y al lado de aquella de daño a la persona y, además, expresó, que observaba con preocupación que en la reforma en marcha de dicho código, al cumplirse su primer decenio de vigencia, no se enmendara ese error.

La respuesta a la precisa observación de Jorge Mosset Iturraspe la debemos encontrar en lo que se llama "la historia interna" del Código Civil de 1984, es decir, aquella que no aparece recogida por ningún historiador, que no está escrita ni ha sido revelada. En efecto, como lo narráramos en una nota a pie de página de nuestra ponencia «El daño a la persona en el Código Civil peruano", presentada en el Congreso Internacional reunido en Lima en agosto de 1985, el lograr que los codificadores del 84 aceptaran introducir la novísima voz -en aquellos años- de "daño a la persona" fue el resultado de permanentes discusiones y replanteos, ya que en el Proyecto concluído por la Comisión Revisora no se admitió la incorporación al Código Civil del daño a la persona. Prácticamente, el daño a la persona había quedado excluído del articulado del Código del $84^{31}$.

Ocurrió, sin embargo, un hecho imprevisto. En efecto, se presentó una ocasión inesperada y propicia para insistir discretamente en el tema. Pocos días antes de la promulgación del Código, fijada para el 24 de julio de 1984, se celebró con fecha 3 del mismo mes en el despacho del ministro de Justicia de aquel entonces, profesor Max Arias Schreiber, una reunión de coordinación con los integrantes de la Comisión Reviso$\mathrm{ra}$, con la finalidad de dar los últimos retoques al ya aprobado Proyecto de Código. A esta reunión fuimos invitados por el ministro junto con algunos otros pocos miembros de la Comisión Reformadora.

31 Fernández Shssarfico, Carlos, "El daño a la persona en el Código Civil peruano de 1984 y el Código Civil italiano de 1942» en El Código Civil peruano y el sistema juridico latinoamericano, p. 254. 
Fue en aquella reunión del 3 de julio de 1984 -es decir, 21 días antes de la promulgación del Código- que se logró introducir en el artículo 1985 el daño a la persona al lado del daño emergente, del lucro cesante y del daño moral que aparecían en este numeral. No se pudo lograr lo más: eliminar del texto de este artículo, por repetitiva, la voz daño moral. Era peligroso insistir en este sentido, ya que se corría el riesgo de reabrir un debate que podría haber concluído con la confirmación del acuerdo adoptado en precedencia por la Comisión Revisora. Es decir, la no inclusión del daño a la persona. Preferimos, ante esta eventualidad y con sentido común, lo bueno en lugar de lo óptimo.

En nota que figura en la ponencia antes referida, redactada en 1985 , explicábamos la razón por la que se mantuvo la voz daño moral en el citado artículo 1985, lo que aparecía como una contradicción con referencia a nuestros antiguos postulados sobre el tema. En dicha nota decíamos textualmente que "si bien el 3 de julio de 1984 se obtuvo que la Comisión Revisora incorporara el daño a la persona en el artículo 1985 del Código Civil peruano, ubicado dentro de la responsabilidad civil extracontractual, no se pudo conseguir la eliminación del concepto de daño moral -dentro de su restringida acepción de afrenta al sentimiento- en tanto constituye un aspecto específico del daño a la persona que, indudablemente trasciende lo que es puramente su vertiente sentimental». Es decir, dejábamos sentada nuestra posición al respecto.

La incorporación del daño a la persona cuando el Código se hallaba en vísperas de ser promulgado no permitió, como hubiera sido deseable, que se pudiera otorgar un tratamiento sistemático al daño a la persona dentro del articulado del Código Civil. Esta fue la razón por la cual los textos de los artículos 1984 y 1322 no pudieran ser oportunamente enmendados y concordados con el artículo 1985 en referencia. Es por ello que en el artículo 1984 se alude y se desarrolla exclusivamente la materia concerniente al daño moral en vez de centrarse sobre el genérico daño a la persona. En este mismo sentido, el artículo 1322, ubicado dentro de la responsabilidad civil contractual, se refiere también solamente al daño moral prescindiéndose de la voz daño a la persona. No obstante, el autor y ponente de dicho numeral, tal como se desprende de la correspondiente Exposición de Motivos, le otorga a la voz daño moral los mismos genéricos alcances que el daño a la persona ${ }^{32}$.

32 En la «Exposición de Motivos y Comentarios» al Código Civil peruano de 1984 (Lima, 1988, T.V) al comentarse el Art. 1322 en lo que concierne al daño moral se expresa textualmente en la página 449 lo siguiente: "Daño moral es el daño no patrimonial, es inferido a los derechos de la personalidad o a valores que pertenecen más al cam- 
En resumen, constituyó un inesperado pero feliz logro incluir la voz daño a la persona en el artículo 1985 del Código Civil de 1984 pocos días antes de su promulgación y cuando el trabajo de la Comisión Revisora había concluído. Esta incorporación, como lo hemos expresado en precedencia, hubiera corrido serio peligro de no concretarse si, dados los antecedentes expuestos, se hubiera reabierto un debate en el cual, en mérito a la novedad de la figura, no se habría acordado, muy probablemente, tal inclusión. El costo de dicha incorporación fue el de no insistir en replantear dicho debate con la finalidad de obtener, como lo pretendíamos, la eliminación de la voz daño moral tanto en el artículo 1985 como en los artículos 1984 y 1322 del mencionado Código Civil.

La incorporación en el artículo 1985 del Código Civil peruano de la obligación de reparar el daño a la persona, sin limitación de ninguna especie, a diferencia de los pocos otros códigos que la incluyen con graves restricciones, constituye una novedad en la codificación civil comparada, tal como se ha puesto de manifiesto por los comentaristas de dicho cuerpo legal ${ }^{33}$.

Como se ha expresado, hubiera sido deseable excluir la voz daño moral no sólo del texto del artículo 1985 del Código sino que también habría sido oportuno sustituir coherente y sistemáticamente dicha expresión por la de daño a la persona en el artículo 1322, así como reformular el artículo 1984 dedicado a la regulación del daño moral. Ello, como decimos, no fue posible en aquella oportunidad. Esperamos que en un futuro, después de una necesaria sedimentación de las ideas y como una demostración de apertura mental frente a las nuevas realidades, se acceda a corregir los yerros que observa Mosset Iturraspe -que compartimos plenamente- y que se escuche su razonada y autorizada recomendación, que compartimos, en el sentido de no mantener tales errores.

po de la afectividad que al de la realidad económica». Como se advierte de la lectura de este comentario, el ponente del Libro de las Obligaciones del Código de 1984 se inclinó por una interpretación amplia del concepto de daño moral a fin de incluir dentro de sus alcances no sólo al daño a la esfera afectiva del sujeto sino, en general, a los daños inferidos a la persona en cualquiera de sus múltiples aspectos.

33 Entre ellos ver Mosset Iturraspe, Jorge, El valor de la vida humana, RubinzalCulzoni, Santa Fe, 1991, 3a. edición, p. 327 y ss. y "El daño fundado en la dimensión del bombre", en Revista de Derecho Privado y Comunitario, Rubinzal-Culzoni, Santa Fe, No. 1, 1992, p, 22 y ss. 


\section{d. Sentido restringido y amplio del «daño moral»}

Existe una importante y extendida tendencia doctrinaria que ha encontrado una peculiar solución para superar el problema que venimos tratando. Ella consiste en distinguir, para tal efecto, dos conceptos diferentes de daño moral: el que denominan restringido o restrictivo y el que llaman genérico. Dentro de este planteamiento, el significado otorgado al daño moral en sentido restringido equivaldría a su tradicional contenido que no es otro que la formulación, esquemática y simplista, de dolor o sufrimiento. Es del caso advertir, por lo demás, que en esta hipótesis, como es sabido, la designación de daño moral no toma en cuenta el aspecto del ser humano que se lesiona -que es su esfera afectiva o sentimental- sino que se hace referencia a la consecuencia del daño que es, precisamente, dolor o sufrimiento.

No podemos perder de vista que el ser humano puede padecer dolor o sufrimiento como resultado de otro tipo de lesiones a otros aspectos de la multifacética personalidad humana que no es, precisamente, aquella esfera afectiva o sentimental. Así, se puede sufrir o sentir dolor por una agresión fisica o verbal, por un atentado contra la verdad personal o contra el honor y en tantos otros casos que sería largo enumerar. Por ello, como señalaremos más adelante, deberíamos tener presente, a propósito del daño, una doble clasificación que contribuye a aclarar la temática que venimos abordando, por la cual se distinguen los daños en función del ente afectado de las consecuencias que ellos generan.

En efecto, consideramos que existe, de conformidad con la realidad del mundo, una primaria clasificación del daño según sea el tipo de ente afectado. En este sentido podemos referirnos a un daño subjetivo, que lesiona al ser humano en sí mismo, y un daño objetivo, que se centra en las cosas del mundo, en el patrimonio del ser humano. Pero, al lado de esta primaria distinción, cabe situar aquella otra que se refiere al daño ya no en función del ente dañado sino en razón de las consecuencias que de él se derivan, ya sea tratándose tanto de la lesión al ser humano mismo como a las cosas que posee.

Como está dicho, la primera de tales distinciones tiene en consideración la naturaleza misma del ente dañado y, la segunda, toma en cuenta las consecuencias que produce el daño en cada uno de los entes que pueden ser afectados, es decir, tanto el ser humano como su patrimonio. Consecuencias que son peculiares, que se diferencian, precisamente, sobre la base de la diversidad ontológica que existe entre los bienes lesionados por el daño.

Aunque daño y consecuencia conforman un proceso inescindible, 
cabe distinguir uno de la otra para el efecto de aplicar, en cada caso, una correcta técnica jurídica tanto para la protección del objeto como para la reparación del daño. Lo dicho sustenta nuestra afirmación precedente en el sentido que dolor y sufrimiento son «consecuencias» de la lesión a un determinado aspecto de la persona. A los juristas decimonónicos se les ocurrió llamar «moral» al dolor o sufrimiento derivado de la lesión a una particular esfera del ser humano como es la afectiva o sentimental. Ellos también determinaron, sin mayor fundamento, que la persona colectiva o jurídica se designase como persona «moral». En este último caso, se ha logrado superar la tradición ya que son escasos los que siguen designando a la persona «jurídica» como persona «moral». ¿Acaso se descubrió tardíamente que lo moral y lo jurídico, no obstante la vinculación existente, pertenecían a dos distintas esferas del ser humano, subjetiva la una e intersubjetiva la otra?

Es importante tener en consideración la naturaleza del ente dañado ya que, como se ha expresado, de ello depende la técnica, el tipo o modalidad de protección jurídica que debe otorgársele al ente así como la manera adecuada de indemnizar el daño sufrido. Algunas veces, en el aula, ante los alumnos, solemos decir que las técnicas de protección de una piedra son distintas de aquellas que se debe brindar a una copa de cristal, a un perro o al ser humano. Así como cada ente exige una determinada vía de conocimiento para acceder a él, así también cada ente exige una técnica de protección adecuada a su calidad ontológica y, llegado el caso, una peculiar modalidad de reparación del daño que se le hubiere ocasionado.

Por lo anteriormente expuesto, somos del parecer que ha contribuído a una falta de precisión en la cuestión atinente a distinguir con pulcritud conceptual el «daño moral» del daño a la persona, el no haber considerado que no cabe confundir el «ente dañado» de las «consecuencias" derivadas de su correspondiente lesión. Es diverso el hecho que el daño incida sobre el ente denominado «persona» del tipo o modalidad de las consecuencias que puedan generar los múltiples y específicos daños a dicho ente. Una de dichas consecuencias es el dolor o sufrimiento que originan ciertos tipos de daño. Entre estos cabe señalar el dolor o sufrimiento que se deriva de una lesión a la esfera afectiva o sentimental del ser humano, el que tradicionalmente se ha identificado con la expresión «moral». Desde nuestro punto de vista, contrariamente a lo que generalmente acontece cuando se trata de indemnizar un daño, no partimos de las "consecuencias" del daño sino de la naturaleza del ente dañado. $Y$, si se trata del ser humano, interesa precisar, prioritariamente, qué aspecto o aspectos son los que han sido lesionados. Luego 
se determinan las específicas consecuencias de la lesión. No podemos, por consiguiente, partir genéricamente de un «dolor» o «sufrimiento» para caracterizar el daño sufrido, ya que el dolor tiene diversos orígenes, los que no se limitan tan sólo a los que se generan por una lesión a la esfera afectiva o sentimental del sujeto.

Un sector de la doctrina al tomar conciencia que al lado de la lesión a la esfera afectiva o sentimental de la persona se presentaban muchísimas otras lesiones al ser humano, no encontró mejor fórmula que en vez de adoptar una nueva genérica denominación que las comprendiera -como sería el caso de la expresión "daño a la persona»prefiriera, sustentándose en nuestro concepto en una mal entendida tradición, incluirlas, sin más, dentro del hasta ese momento restringido y específico concepto de daño moral. De este modo, sin mayor esfuerzo, se decidió por dicho sector de la doctrina que esta restrictiva expresión -con la que hasta ese momento se distinguía un caso concreto de daño- cubriera una multiplicidad de hipótesis de daños que no se identificaban, precisamente, con el contenido conceptual de su precisa y tradicional noción. Es decir, se produjo lo que podríamos llamar, apelando a una metáfora económica, una «hiperinflación» conceptual de la tradicional noción de daño moral. Se convirtió, así, en lo que en el lenguaje corriente solemos designar como «un cajón de sastre», es decir, aquel espacio donde se yuxtaponen una infinidad de objetos heterogéneos.

Es así que bajo el concepto de "daño moral» se crearon dos diversas situaciones jurídicas -una restringida y otra amplia- dando lugar a frecuentes e innecesarias confusiones. Al respecto nos preguntamos, ¿así como los economistas aplican «reajustes» para combatir la hiperinflación, no podríamos los juristas adoptar las medidas oportunas para rectificar un error terminológico y conceptual en la medida que no encuentra su correlato en la realidad? Es decir, un innecesario error que origina confusiones y dificultades que los juristas podrían superar fácilmente si no persistieran en utilizar la expresión «moral», a la manera de los juristas franceses del siglo XIX, para designar una institución exquisitamente «jurídica» y de una mucha más amplia comprensión conceptual.

Así, entre otros autores, Jorge Gamarra, en reciente obra, que data de 1994, reconoce este hecho al expresar que la definición tradicional y restringida de daño moral resultaba «incompleta». Para subsanar esta deficiencia, el prestigioso profesor uruguayo postula, como solución, que el concepto de "daño moral» abarca, en realidad, un sector mayor de daños, por lo que esta noción coincide enteramente con la esfera del daño no patrimonial. Por lo tanto, es más adecuado hablar de daño no 
patrimonial ${ }^{34}$. Reconoce explícitamente, de este modo, que existe una opción sobre dos nociones distintas de daño moral (restringida la una y amplia la otra).

El mencionado autor, siguiendo a Vaz Ferreira, es de la opinión que el dolor no es esencial al daño moral por lo que «desaparece la única nota que justificaría distinguir al daño moral dentro del daño no patrimonial, y la base para crear dos especies diversas dentro del daño no patrimonial» ${ }^{35}$. Según el profesor Gamarra son figuras que responden a una misma definición, es decir, que carecen de efectos patrimoniales y tienen la misma regulación. Prefiere, por consiguiente, la denominación de daño no patrimonial para englobar en ella las dos figuras del daño moral, la restringida y la amplia.

Frente a las afirmaciones de Jorge Gamarra es dable formular algunas observaciones. En primer lugar, habría que inquirir sobre cuál sería la razón por la que se debe seguir utilizando la tradicional expresión de «daño moral» para referirse al daño a la persona, que Gamarra y otros autores equiparan al daño no patrimonial, situación que, de hecho, causa confusión sobre todo entre los iniciados en la disciplina jurídica. La segunda observación se refiere a que, en el supuesto negado de admitir tal equiparación entre daño moral y daño no patrimonial, cabe preguntarse por cuál sería la razón para designar como "no patrimonial»-privilegiando así al patrimonio sobre el ser humano- a lo que es, simple y llanamente, un daño a la persona en toda la extensión del concepto. Nos parece que ambas son dos seculares tradiciones que ha llegado la hora de cuestionar a la luz de los hallazgos de la Antropología Filosófica.

No advertimos el motivo, aparte del probable culto a una tradición mal entendida o a la ley del mínimo esfuerzo, para seguir denominando como «moral» un daño de indudable naturaleza y consecuencias jurídicas. Al compartir las precisiones de Jorge Mosset Iturraspe no comprendemos por qué debemos seguir rindiendo tributo a una tradición que el tiempo ha desdibujado, que ha sido desmentida por la realidad. No entendemos, por consiguiente, por qué se continúa denominando «moral» a lo «jurídico». Si la gran mayoría de los autores y de los cuerpos legales han sido capaces de abandonar, por no ser descriptiva de su objeto, la tradicional expresión de persona «moral» y sustituirla por la de persona "jurídica»-que en verdad es colectiva-, no vemos la razón para que en un caso similar, como es el del daño moral, no se produzca idéntico

\footnotetext{
34 Gamarra, Jorge, Tratado de Derecho Civil Uruguayo, Fundación de Cultura Universitaria, Montevideo, 1994, p. 15.

35 Gamarra, Jorge, ibidem. p. 15.
} 
cambio. ¿Por qué asimilar a la expresión «moral», que tradicionalmente se ha empleado para significar dolor o sufrimiento derivado de una lesión a la esfera afectiva, los múltiples y diversos daños que se producen en agravio de la persona, lesionando su cuerpo, su psique o su proyecto de vida? Nos preguntamos, asimismo, ¿qué tiene que ver todo esto, que es estrictamente «jurídico», con lo «moral»? Parecería que, como en otros tiempos que son ya historia, seguimos confundiendo empecinadamente lo "moral», que se enraíza en la pura subjetividad, con lo jurídico que aparece a partir de la intersubjetividad.

Cuando escribimos estas líneas emergen en nuestra memoria dos nombres ilustres que son orgullo del pensamiento jurídico latinoamericano. Nos referimos a Teixeira de Freitas y Vélez Sarsfield. Admiramos, a más de un siglo y medio de distancia en el tiempo, su lucidez, su coraje intelectual para enfrentar -en la segunda mitad del siglo XIX- el tradicional pensamiento dominante sobre el tratamiento jurídico del concebido, al que se le consideraba, por todos los códigos civiles del mundo, en aquel entonces y hasta ahora, como una simple ficción. Es decir, un ente que carecía de significación para el Derecho y que, cuando se suponía que debería ser lo que es, dejaba de serlo por cuanto ya era un nacido, una persona natural. Por ello, resumiendo esta peculiar situación en que el Derecho había sumido al concebido, decíamos que éste «es lo que no es y que, cuando es, ya no es".

Según la hasta ahora dominante teoría de la ficción, se ignoraba que el concebido era realmente un ser humano, que debería ser una realidad para el Derecho, un sujeto. Como es sabido, se le consideraba como una ficción, "algo» que debería esperar nacer para recién adquirir la categoría jurídica de sujeto de derecho. Pero, como es evidente, cuando el concebido nacía ya no era tal, pues nos hallamos en este instante existencial ante una persona natural.

Tanto Teixeira de Freitas, a mitad del siglo pasado, como Vélez Sarsfield en 1869, intuyeron la realidad del concebido como ser humano $y$, con valentía que nos enorgullece como latinoamericanos tributarios de su pensamiento, lo consideraron y lo denominaron como epersona por nacer», desafiando de este modo una consagrada, férrea y unánime tradición. Su convicción, que superaba las «construcciones» conceptuales y que más bien se inspiraban en la observación de la realidad y las voces de la ciencia, fue ignorada o silenciada por cerca de siglo y medio hasta que llegó el Código Civil peruano de 1984 que, dentro de su línea de pensamiento y en sintonía con la ciencia, otorgó al concebido la calidad de "sujeto de derecho". El ejemplo creativo y el coraje intelectual de Teixeira de Freitas y de Vélez Sarsfield, estamos seguros, han de ser mo- 
tivo de constante inspiración para los juristas latinoamericanos, los que no estamos obligados, siempre y necesariamente, a recoger y consagrar teorías sin antes someterlas a un repensamiento y a una reflexión crítica.

\section{e. ¿ Daño a la persona o daño no patrimonial ?}

Una tercera observación sobre el tema que nos ocupa se refiere al intento de equiparar la noción de daño a la persona con el concepto de daño no patrimonial. Aparte de que no llegamos a entender la preferencia de los juristas por la expresión "patrimonio» sobre la de «persona», consideramos que no siempre el daño a la persona tiene consecuencias no patrimoniales. Por el contrario, generalmente, a las consecuencias de carácter no patrimonial se suman otras de naturaleza patrimonial. Es decir que, desde nuestro punto de vista, no cabe equiparar el concepto de "daño a la persona» con el de "daño no patrimonial». Ello, siempre dentro de nuestra óptica, supone mezclar dos niveles conceptuales diversos como son, de un lado, la naturaleza del ente dañado y, del otro, las consecuencias que generan dichos daños, ya sea a la persona o al patrimonio o a ambos.

En un trabajo publicado hace más de tres años expresábamos que debíamos encaminarnos a una nueva sistematización del daño a la persona $^{36}$. En efecto, en aquella oportunidad sosteníamos que, a nuestro parecer, y tal como lo hemos adelantado, la primaria clasificación del daño debería atender a la naturaleza del ente dañado, ya que las técnicas de protección y de reparación jurídica del ente variaban según los casos. A este propósito proponíamos que «la primera distinción que habría que hacer respecto al daño, dada su importancia teórica y práctica, es la que se sustenta en la calidad ontológica del ente afectado por dicho daño». Es decir, que debía privilegiarse la calidad del ente dañado a las "consecuencias» producidas a raíz del daño ${ }^{37}$ Por lo expuesto, éramos del parecer que, primordialmente, debería atenderse a si el ente dañado es una

36 Ver Fervánllz Sessarfio, Carlos, "Hacia una nueva sistematización del daño a la persona", en Estudios en Honor de Pedro J. Frias, Academia Nacional de Derecho y Ciencias Sociales de Córdoba, T.II, 1994, p. 1087 y ss. Este trabajo también se publicó en Cuadernos de Derecho, 3, Universidad de Lima, 1993, p. 28 y ss. y en Ponencias Primer Congreso Nacional de Derecho Cinil y Comercial, Universidad Nacional Mayor de San Marcos, Lima, 1994, p. 23 y ss.

37 Fernández Sfessarecio, Carlos, "Hacia una nueva sistematización del daño a la persona», en Cuadernos de Derecho, 3, p. 32. 
cosa u objeto del mundo, por más valioso que fuera o si, por el contrario, el ente dañado es nada menos que el ser humano, el sujeto de derecho.

Nadie puede discutir la fundamental diferencia ontológica que existe entre el ser humano, que es libertad y sensibiliza valores, y las cosas del mundo que, contrariamente, carecen de libertad, no vivencian valores y son acabadas, terminadas, macizas. Esta diferencia marca el diverso tratamiento técnico-jurídico que merece cada una de estas tan disímiles calidades de entes. Ello, con mayor razón, debe manifestarse cuando se trata de apreciar la magnitud del daño, considerado en sí mismo, y sus consecuencias, ya sean éstas patrimoniales o no patrimoniales.

Como es fácil percibir, la posición antes sustentada se inspira en una concepción personalista o humanista del Derecho, que coloca al ser humano, y no al patrimonio, como eje y centro de la disciplina jurídica. Razón que ha llevado a ciertos autores a concentrar su preferente atención en torno a la víctima del daño, ante la humana necesidad de que ella no quede sin reparación. Esta actitud supone que al derecho le interesa prioritariamente atender a la víctima frente a la indagación destinada a determinar el grado o intensidad de la culpa del agente del daño que, en algunos casos, como señala Mosset Iturraspe, pareciera ponerse del lado del agente del daño con el propósito de diluir la debida indemnización.

En virtud de lo expuesto, apreciábamos que existen dos tipos básicos de daños si se tiene en cuenta, como se ha dicho, la naturaleza misma del ente que ha sufrido sus consecuencias. Así, y tal como se ha señalado, es posible hacer una primera y amplia distinción que atiende a la calidad ontológica de los entes pasibles de ser dañados. En este sentido, como se ha mencionado, encontramos, de un lado, a los seres humanos, sujetos de derecho y, del otro, a las cosas u objetos del mundo, de los cuales se valen instrumentalmente las personas para realizarse. De ahí que podamos referirnos al daño subjetivo, que es el que agravia o afecta a los seres humanos, y al daño objetivo, que es el que incide sobre los objetos que integran el patrimonio de las personas. El primero de dichos daños, por lo tanto, se refiere al "ser humano", considerado en sí mismo, y el segundo de ellos atiende al "haber» del sujeto de derecho. Esta constituye, desde nuestra óptica, la primera y básica clasificación de los daños.

A nadie escapa, por lo demás, que la diversidad ontológica entre el ser humano y las cosas que integran su haber o patrimonio, se refleja en las especiales y distintas características que asume la indemnización por las consecuencias derivadas del daño que afecta específicamente a cada una de tales calidades de entes. No se puede, «con un criterio economicista y materialista, dejar de reconocer el diverso rol que cumple la in- 
demnización en el caso que se destruya una cosa que cuando se agravia al ser humano mismo, creador, eje y centro del Derecho» ${ }^{38}$.

El daño subjetivo o daño a la persona es aquel cuyos efectos recaen en el ser humano, considerado en sí mismo, en cuanto sujeto de derecho, desde la concepción hasta el final de la vida. Por la complejidad del ser humano, los daños pueden afectar alguna o algunas de sus múltiples manifestaciones $o$ «maneras de ser».

Como el ser humano es una unidad psicosomática, sustentada en la libertad, los daños que se le causen pueden incidir ya sea en su cuerpo, en sentido estricto, o en su psique o afectar su propia libertad. El daño psicosomático puede recaer directamente en el cuerpo o soma del sujeto o en la psique, bajo el entendido que en cualquier caso el daño a una de tales esferas repercute, en alguna medida, en la otra sobre la base de la inescindible unidad antes referida.

El daño psicosomático puede desglosarse a su vez, para fines puramente descriptivos o didácticos o para orientar mejor la debida reparación, en daño «biológico» y daño a la «salud». En realidad, metafóricamente hablando, se trata de dos caras de una misma moneda. El daño biológico representa la vertiente estática y el daño a la salud la vertiente dinámica del genérico daño psicosomático.

El daño biológico se identifica con la lesión, considerada en sí misma, causada a la persona víctima del daño. En el daño denominado «biológico» se compromete, en alguna medida, la integridad psicosomática del sujeto, de modo directo e inmediato, causándole heridas de todo tipo, lesiones varias, fracturas, perturbaciones psíquicas de diversa índole. Las consecuencias de una acción dañina contra el cuerpo o soma son, generalmente, visibles y elocuentes al margen, claro está, del preciso diagnóstico médico-legal que formula un pronóstico de las mismas.

En cambio, una lesión psicosomática que incide preferentemente en la psique resulta, como es obvio, menos elocuente y visible y probablemente más dificil de diagnosticar. $\mathrm{Y}$, en ciertos casos, puede pasar inadvertida para cualquier persona que no sea un médico especialista en la materia. La lesión que afecta la psique, en cualquiera de sus manifestaciones, puede ser el resultado de una previa agresión somática aunque puede también presentarse inicialmente desvinculada de dicha agresión, no obstante las conexiones existentes en virtud de la unidad psicosomática en que consiste la naturaleza del ser humano.

38 FERNÁNDHZ SESSAREGo, Carlos, "Hacia una nueva sistematización del daño a la persona", en Cuadernos de Derecho, 3, p. 33. 
El daño que compromete preferentemente la esfera síquica del sujeto puede incidir primaria y notoriamente en alguna de las manifestaciones en que teóricamente solemos descomponerla, como son el aspecto afectivo, el volitivo y el intelectivo. Precisamente, cuando la incidencia se presenta fundamentalmente en la esfera afectiva o sentimental solemos aludir al daño moral en su restringido sentido tradicional de «dolor de afección".

El daño psicosomático por lo tanto, puede incidir ya sea sobre el soma o cuerpo, en sentido estricto, o sobre la psique. En el primer caso se suele denominar como daño físico, mientras que, en el segundo, se alude al daño psíquico. En cualquier caso una lesión somática repercute de diferente manera en el psiquismo según sea el sujeto de que trate $y$, viceversa, un daño psíquico suele tener una manifestación somática.

El daño físico incide sobre el cuerpo o soma y puede consistir en contusiones, heridas, fracturas, de todo tipo y magnitud. El daño psíquico se configura por «la alteración o modificación patológica del aparato psíquico como consecuencia de un trauma que desborda toda posibilidad de elaboración verbal o simbólica» ${ }^{39}$. Es decir, el daño psíquico supone una modificación o alteración de la personalidad que se «expresa a través de síntomas, inhibiciones, depresiones, bloqueos..." ${ }^{40}$.

La lesión en sí misma que constituye, como se ha señalado, el daño biológico, debe ser apreciada por sus particulares características por un médico-legista, el que ha de formular un diagnóstico y un pronóstico de la lesión, determinando su magnitud y peculiaridades.

El daño a la salud, en cambio, alude a las inevitables y automáticas repercusiones que produce cualquiera lesión psicosomática en el bienestar de la persona, con prescindencia de su magnitud e intensidad. El daño a la salud es de tal amplitud que compromete el estado de bienestar integral de la persona. De ahí que, coincidiendo con Bargagna, podemos sostener que abarca, por consiguiente, las normales y ordinarias actividades del sujeto, ya sean ellas, entre otras, laborales, domésticas, sexuales, recreativas, sentimentales, de relación social, deportivas, entre otras ${ }^{41}$.

El desencadenamiento de un daño inferido a alguna manifestación de la esfera psicosomática repercute de inmediato y automáticamente, en alguna medida, en la salud del sujeto, afectándola en diverso grado e intensidad según los casos. Reiteramos que, siguiendo la orientación de la

\footnotetext{
34) Milmaitnkt, José E., El daño psíquico, p. 70.

40) Milmaitnt, José E., ibidem. p. 74.

41 BARCiAGiNA, Marino, "Rilievi critici de spunti ricostruttivi» en La palutazione del danno alla salute, Cedam, Padova, 1986, p. 170
} 
Organización Mundial de la Salud, entendemos que con el concepto salud se alude a la más amplia noción de bienestar integral del sujeto. De ser así, en algún momento deberíamos también adecuar el lenguaje a esta nueva realidad, de ser ella admitida por un sector mayoritario de la doctrina, sustituyendo, cuando el respectivo ordenamiento jurídico positivo lo permita, la expresión daño a la salud por la de daño al bienestar del sujeto. $\mathrm{O}$, por el contrario, precisar conceptualmente que la salud, en sentido estricto, es un importante componente del genérico bienestar integral del sujeto ${ }^{42}$.

Dentro de la orientación anteriormente señalada, la Constitución peruana de 1993, en su artículo $2^{2}$ inciso 1 , ha incorporado como derecho de la persona que merece tutela el denominado derecho al bienestar.

El daño a la salud, por lo precedentemente expresado, compromete, por lo tanto, el entero «modo de ser» de la persona. Supone, por decirlo de alguna manera, un déficit de diversa magnitud e intensidad en el bienestar integral del ser humano.

De lo expuesto se concluye que el daño biológico, en cuanto vertiente estática del daño psicosomático, como el daño a la salud, que representa la dimensión dinámica de dicho daño, constituyen sólo dos aspectos de una misma realidad en cuanto el ser humano es una inescindible unidad psicosomática. De lo dicho se desprende, por consiguiente, que ambos tipos de daño sólo pueden ser teóricamente diferenciados para el efecto de su debida evaluación y ulterior reparación.

Al lado de esta clasificación del daño en función de la naturaleza del ente afectado, a la cual nos hemos referido en los párrafos precedentes, cabe formular una segunda clasificación, ya no en función de la calidad ontológica del ente dañado, sino en virtud de las consecuencias derivadas de cada uno de tales daños. Son, pues, dos materias distintas, que no cabe confundir si pretendemos clarificar nuestra visión sobre el contenido y alcances del daño a la persona. La primera, reiteramos, se sustenta en la naturaleza misma del ente dañado -y es de fundamental importancia para la reparación del daño- y la segunda se contrae a las consecuencias mismas del daño producido a cualquiera de los entes afectados.

En atención a las consecuencias derivadas del daño se pueden distinguir las que la mayoría de autores designan como «no patrimoniales» o «extrapatrimoniales» -y que nosotros, desde una óptica antropológica,

\footnotetext{
42 La Constitución peruana de 1993 incluye al bienestar entre los derechos fundamentales en el inciso 1 del artículo $2^{\circ}$, mientras que en el artículo $7^{\circ}$ proclama el derecho a la salud.
} 
preferimos aludir como "personales»- de aquellas otras consecuencias conocidas como "patrimoniales» que nosotros, asimismo y por idéntica razón, optamos por nominarlas como «no personales» o «extrapersonales $\gg^{43}$.

Si consideramos el daño a la persona en toda su latitud conceptual, advertimos que puede generar consecuencias tanto personales -o no patrimoniales- como no personales o patrimoniales- $o$, como ocurre frecuentemente, puede originar, de modo simultáneo, ambos tipos de consecuencias. Así, por ejemplo, a raíz de un accidente de automotor, se plantea la hipótesis de que la persona del conductor de uno de los vehículos sufre graves lesiones que requieren su hospitalización ya que, como consecuencia de las mismas, pierde los dos brazos. La pregunta que surge frente a este caso es, en primera instancia, si se ha producido o no un daño a la persona y, de ser así, en segunda instancia, si de este daño se genera tan sólo una consecuencia personal o no patrimonial o si también y al mismo tiempo se deriva una consecuencia de orden no personal o patrimonial. El sentido que conlleve la respuesta nos permitirá apreciar si es correcto, como propone un sector de la doctrina y en especial el profesor Jorge Gamarra, identificar, sin más, daño a la persona, que atiende a la naturaleza del ente dañado, con daño no patrimonial (o personal) que se refiere a sólo una de las dos consecuencias que puede producir el daño a la persona.

En el caso propuesto no cabe duda que se han producido daños a un ente que es una persona humana. Como no se trata de una mera cosa del mundo exterior, que sería la otra única posible alternativa, no podemos dudar que estamos frente a un daño a un ente que no es otro que la persona. Así quedaría respondida la primera cuestión que hemos planteado.

Luego de haber precisado la calidad ontológica del ente dañado es menester, en segundo término, apreciar que tipo o tipos de consecuencias se derivan de los daños de que ha sido víctima la persona. En la hipótesis que se ha planteado advertimos, de inmediato, que la víctima presenta lesiones múltiples, heridas, fracturas, contusiones. Si apreciamos tan sólo y en sí mismas las lesiones que se han producido estaríamos frente a lo que hemos denominado como daño biológico. Este daño es susceptible de ser diagnosticado por un médico legista quien determinará su magnitud y sus efectos. Estas lesiones deben ser materia de una justa reparación utilizándose para ello, cuando existen, los baremos o ta-

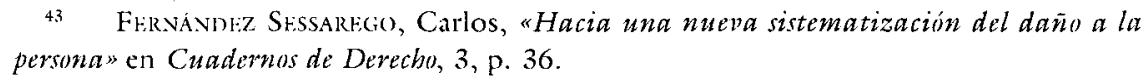


blas de infortunios o, en su defecto, el principio de equidad, o ambos criterios.

Pero, a su vez, dichas lesiones psicosomáticas -daño biológico- causan un deterioro en la salud de la víctima, alteran en alguna medida su bienestar integral. Este efecto debe ser apreciado y reparado por el juez sobre la base del informe médico-legal, empleando para el efecto el criterio de equidad luego de observar y calibrar las consecuencias producidas. Daño biológico, o sea la lesión considerada en sí misma, y daño a la salud, que es su repercusión en el bienestar integral de la persona, deben ser considerados, finalmente, como un todo para el efecto de fijar la correspondiente reparación, no obstante que la apreciación por el juez de cada uno de dichos daños obedece, como se ha señalado, a distintos criterios.

Ambos daños - el daño biológico y el daño a la salud-generan consecuencias que no son apreciables, directa e inmediatamente, en términos dinerarios. No generan, por consiguiente, consecuencias de carácter patrimonial o extrapersonal sino, más bien, se trata de consecuencias de orden personal o no patrimonial. Son daños ciertos y efectivos que, en ningún caso, pueden soslayarse de parte del juez. Felizmente los criterios puramente patrimonialistas van siendo desplazados en el mundo actual al lugar que, sin desconocerlos, jerárquicamente les corresponde, es decir, subordinados a la privilegiada protección jurídica que merece el ser humano. Cada vez se comprende con mayor claridad, pese al embate de los materialistas de toda laya y de los absolutamente pragmáticos, que el ser humano es un fin en sí mismo y que el patrimonio es un instrumento indispensable a su servicio ${ }^{44}$.

La cada vez mayor difusión y comprensión de los principios personalistas ha provocado una revisión o replanteo de la institucionalidad jurídica. De ello hay innumerables pruebas en la doctrina, la jurisprudencia y la legislación contemporánea. Esta nueva actitud llegó, como no podía ser de otra manera, al campo de la responsabilidad civil. Es por ello que, de hacer girar el problema en torno al agresor y a su consiguiente responsabilidad, se centró la atención de los juristas en torno a la justa reparación de los daños sufridos por el ser humano. De ahí que pueda sostenerse que la visión moderna sobre el derecho de daños responde

44 El daño a un objeto puede producir, igualmente, al lado de un daño no personal o patrimonial un daño personal o extrapatrimonial. Para ilustrar el caso podemos recurrir al difundido ejemplo por el cual un tercero pierde la única fotografia de un ser muy querido, la misma que tenía para su propietario un enorme valor afectivo o sentimental mientras que carecía de un valor no personal o patrimonial. 
principalmente a principios humanistas y solidarios. Se protege a la persona por el único y fundamental argumento de su propia dignidad. Es decir, por lo que ella realmente es y representa en el mundo.

No es este el lugar para reproponer un debate que, a nuestro entender, ha sido actualmente superado. Sin embargo, ello no impide formular algunas precisiones al respecto. Nos referimos, en concreto, al argumento central que giraba en torno a la cuestión de si se debía o no repararse un daño a la persona que, no obstante ser cierto y efectivo, no podía ser apreciado en dinero de modo directo e inmediato. De acuerdo con una visión materialista de la vida -de cualquier signo o ideologíadominante en el derecho hasta no hace mucho, sólo era posible reparar las consecuencias del daño que tenían un "precio» en el mercado, que se podía traducir en dinero. De conformidad con esta estrecha concepción, dentro de la cual la vida humana y los derechos fundamentales de la persona carecían de un "precio", resultaba imposible fijar una indemnización como consecuencia de un daño de carácter no patrimonial. Es decir, prevalecía un criterio economicista, dentro del cual se trataba con absoluto desdén -o desprecio- lo que significaba el ser humano, desconociéndose el auténtico valor de la vida humana.

Como argumento para negar tal indemnización se sostenía, por un sector mayoritario de la doctrina, que la reparación de las consecuencias de los daños a la persona que carecían de efectos patrimoniales, era una forma de «materializar» la vida humana. Con este pretextuoso y falaz argumento se dejaban sin reparar los daños cometidos contra la persona, considerada en sí misma, desconociéndose su intrínseco valor. Contrariamente, por cierto, procedía siempre el resarcimiento de los daños que generaban consecuencias patrimoniales. Es decir, se privilegiaba a los entes del mundo exterior, a las cosas, en detrimento del ser humano.

Felizmente, el criterio materialista que campeaba en la responsabilidad civil cuando se trataba de reparar un daño a la persona, va quedando atrás. Son cada día menos numerosos los juristas que sostienen esta actitud. En la Argentina, para citar un caso emblemático, existe, como se ha puesto de manifiesto, una corriente personalista que ha logrado hacer prevalecer un criterio humanista en esta específica área de la responsabilidad civil. Así, hace ya varias décadas, el maestro Orgaz expresó con contundente convicción que "resarcir los daños morales, aunque sea de modo pecuniario -a falta de otro mejor- no es materializar los intereses morales, sino, al contrario, espiritualizar el derecho, en cuanto éste no se limita a la protección de los bienes económicos y rodea también de seguridad aquellos otros bienes no económicos, que son inseparables de la persona hu- 
mana» ${ }^{45}$. Como es obvio, cuando Orgaz escribía este párrafo aún no había aparecido el genérico concepto de daño a la persona por lo cual el maestro argentino utiliza la consagrada expresión de daño moral.

En el «II Congreso Internacional de Daños», reunido en Buenos Aires en 1991, se declaró al respecto que «el enfoque meramente patrimonialista del daño se encuentra en trance de quedar divorciado de las pautas el Derecho en nuestros días". De donde se concluía que debíase jerarquizar "la esfera biológica, espiritual y social del hombre, sin dejar de tener en cuenta que los bienes materiales son necesarios para preservar su dignidad». En esta misma ocasión se estableció, siempre por unanimidad, que «la reparación del daño a la persona debe ser plenamente adecuada a la magnitud de lo que ésta (la persona) representa, descartando las indemnizaciones meramente simbólicas".

Además del daño biológico y del daño a la salud, a los que nos hemos referido en precedencia, hay un daño que frecuentemente se ignora o se olvida por quienes no logran aún descubrir o concebir la calidad ontológica del ser humano como ser libre y temporal, que se propone fines, los mismos que están contenidos en su «proyecto de vida».

La pérdida de los dos brazos de parte de una persona, en el caso del ejemplo propuesto en su lugar, podría traer como consecuencia la frustración de su principal proyecto de vida, expresado a través de su actividad cotidiana, situación en la cual se privaría de sentido la existencia misma de la víctima. Esta es, sin duda, una consecuencia personal o no patrimonial en tanto carece de significación monetaria, directa e inmediata, lo que no quiere decir, obviamente, que se niegue a la víctima una justa satisfacción por el enorme daño que se le ha ocasionado.

Pero, en el caso del ejemplo antes citado, que es el de la víctima de un accidente automovilístico, se aprecia que al lado de las consecuencias no patrimoniales o personales que genera el elocuente daño a la persona, antes mencionadas, se presentan simultáneamente consecuencias exquisitamente patrimoniales o no personales que deben ser también debidamente indemnizadas. Nos referimos al reembolso, entre otros, de los gastos de hospitalización, los honorarios médicos, la adquisición de medicinas, los que pueden considerarse integrantes del denominado daño emergente. Al mismo tiempo, y siempre en el campo de las consecuencias patrimoniales o extrapersonales, debe indagarse si, como consecuencia del daño, el sujeto se halla imposibilitado de realizar su actividad laboral habitual o si a raíz de las lesiones sufridas se ve privado de obtener 
los ingresos que le corresponden o deja de percibir rentas, ganancias o riqueza, en general, pues en esta hipótesis, como es sabido, debe resarcirse el llamado lucro cesante.

De lo expuesto se percibe que el daño a la persona ha producido, al mismo tiempo, consecuencias de carácter patrimonial o extrapersonal al lado de consecuencias de orden personal o no patrimonial. De ahí que el daño a la persona no puede ser caracterizado sólo a partir de las consecuencias que genera ${ }^{46}$.

Después del somero análisis efectuado, y por las razones que de él fluyen, somos de la opinión que no es correcto asimilar, sin más, la noción de daño a la persona, que se centra en la peculiar calidad ontológica del ente dañado, con la de daño patrimonial (o no personal) que incide, ya no en la naturaleza del ente sino, más bien, en uno de los tipos de consecuencias generadas por el daño. Estimamos, por consiguiente, que debe diferenciarse, para estos efectos, la naturaleza del ente dañado de las consecuencias del mismo.

Si nuestras reflexiones no están erradas, deberíamos concluir afirmando la autonomía del concepto de daño a la persona en función de la calidad ontológica del objeto dañado y no tratar de ligarlo a las consecuencias que pueden derivarse de él, las que como hemos apreciado pueden tener un carácter extrapersonal o patrimonial o ser de orden no patrimonial o personal. De ahí que no compartimos la propuesta de quienes equiparan el concepto de «daño a la persona» (o de daño moral en sentido amplio) con la noción de "daño no patrimonial". No siempre el daño a la persona tiene tan sólo consecuencias no patrimoniales o personales sino que, con frecuencia, ellas asumen un carácter extrapersonal o patrimonial. No son las consecuencias del daño, por consiguiente, las que tipifican el daño a la persona. Se debe atender, primariamente a la naturaleza del ente dañado para luego determinar las consecuencias, de cualquier índole, que genere el daño a fin de precisar el mejor y más adecuado modo de repararlas.

\section{4. ¿Existe un daño al proyecto de vida?}

\section{a. Sus supuestos}

Hemos adherido a la filosofía de la existencia que considera que la liber-

46 Frrnándiz ShSsarfi(i), Carlos, "Hacia una nuepa sistematización del daño a la persona", en Cuadernos de Derecho, 3, p. 36. 
tad constituye el ser mismo del hombre. Esta libertad es lo que lo diferencia, radicalmente, de los demás seres de la naturaleza y le otorga dignidad. Se trata de una potencialidad que nos permite decidir, elegir, entre muchas posibilidades de vida, eso que, precisamente, llamamos proyecto de vida o proyecto existencial. Gracias a la libertad somos seres temporales, históricos, estimativos, creativos, proyectivos, dinámicos. Carecería de sentido un ser libre que no fuera, simultáneamente, un ser temporal.

Como lo hemos puesto de manifiesto, el "proyecto de vida» es posible en tanto el ser humano es libre y temporal. Y es que el proyecto surge necesariamente de una decisión libre para su realización en el futuro, ya sea éste mediato o inmediato. Por ello, sólo el ser humano es capaz. de formular proyectos. Es más, no podría existir sin decidir ser lo que pretende ser, es decir, sin proyectar. Libertad y tiempo son, por consiguiente, los dos supuestos existenciales del proyecto de vida. Todos los seres humanos, en cuanto libres, generamos proyectos de vida. Nos proponemos realizarnos, vivir de determinada manera, haciendo aquello que se nutre de nuestra vocación personal.

El proyecto de vida, si bien apunta al futuro y se despliega en el tiempo, se decide en el presente, al cual condiciona el pasado. Como apunta Jaspers, "consciente de su libertad, el hombre quiere llegar a ser lo que puede y quiere sers ${ }^{47}$.

Para decidir sobre un cierto proyecto de vida, que responda a nuestra recóndita vocación personal, debemos valorar, es decir, precisar aquello que para nosotros resulta valioso realizar en la vida, aquello que le va a otorgar un sentido a nuestra cotidiano existir. El proyecto supone trazar anticipadamente nuestro destino, un modo cierto de llenar nuestra vida, de realizarnos. La vivencia de valores le otorga sentido y, por ende, trascendencia al vivir. El proyecto de vida no es concebible sin una vivencia axiológica de parte del sujeto.

Una vez que, por ser libres y tener la capacidad de valorar, decidimos o elegimos un proyecto de vida, tratamos por todos los medios o instrumentos a nuestro alcance de cumplirlo, de concretarlo, de ejecutarlo durante el curso de nuestra vida, salvo que, en algún momento de nuestro existir, cambiemos o modifiquemos, en alguna medida, el proyecto existencial. Al mencionar «medios» nos referimos, en general, a todo aquello de que se vale nuestro ser para realizarse, para convertir en acciones o conductas el proyecto existencial. Entre estos instrumentos 
contamos con nuestro cuerpo o soma, nuestra psique, los «otros», las cosas del mundo. Todo ello, en una u otra medida o manera, contribuye ya sea a la realización exitosa del proyecto de vida o a su fracaso, a su destrucción, a su frustración. La vida, bien lo sabemos por experiencia, está llena de gratificantes realizaciones pero, también, de traumáticas frustraciones.

La libertad, en sí misma, se juega entera en la decisión del proyecto. Su actuación, en cambio, significa su expresión fenoménica, cuya realización o frustración depende de las posibilidades de cada cual, condicionadas por los medios o instrumentos con que cuenta para conseguir este fin.

Para lograr la efectiva realización de nuestro proyecto de vida se requiere contar con posibilidades, empeño, perseverancia, energía, constancia, coraje. De esto somos conscientes, porque son muchos y muy variados los obstáculos que debemos vencer o ante los cuales habremos de sucumbir en la persecución de este propósito. Por eso, como lo recalca Mounier, es del caso recordar que la vida es una guerra civil consigo mismo. La realización del proyecto es una conquista. Es el resultado de una lucha permanente y cotidiana contra los condicionamientos que agobian a la persona. Como expresa Mounier, «hay en mi libertad un peso múltiple, el que viene de mí mismo, de mi ser particular que la limita, y el que le llega del mundo, de las necesidades que la constrinen y de los valores que la urgen ${ }^{48}$. Es decir, como señala el propio Mounier «la libertad se gana contra los determinismos naturales, se conquista sobre ellos, pero con ellos ${ }^{49}$.

Pues bien, después de lo expuesto cabe preguntarse, una vez más, si existe un "proyecto de vida». Por nuestra parte, desde antiguo, estamos convencidos de ello porque, fundamentalmente, tenemos experiencia de nuestra libertad y de nuestra temporalidad, de la vivencia de valores y, por consiguiente, de la formulación de proyectos. Es decir, somos conscientes, de acuerdo con nuestra inclinación vocacional, de lo que hemos elegido realizar en la vida para otorgarle a ésta un sentido, para dignificarla, para encontrar una razón al vivir. Lo que no es poco, si apreciamos en todo su valor y significación el precioso don de la vida.

Somos también generalmente conscientes de nuestras realizaciones, de su ocasional plenitud o de sus frecuentes limitaciones. Pero también se hacen patentes nuestras frustraciones, nuestros fracasos. Tratamos, a 
menudo, de indagar por los condicionamientos, endógenos o exógenos, que han gravitado en nuestros éxitos y, con mayor razón, por aquellos que determinaron nuestras frustraciones.

Después de lo hasta aquí expresado es lícito preguntarse si será posible causar un daño de tal magnitud que frustre nada menos que el radical proyecto de vida de la persona. El mayor conocimiento que en la actualidad se tiene de lo que significa el ser humano, de lo que constituye su estructura, así como de lo que surge de la experiencia del puro vivir, hacen posible una respuesta afirmativa. De ello estamos plenamente convencidos y desearíamos, por consiguiente, contribuir con estas modestas y embrionarias reflexiones a fin de que quienes aún no comparten estas experiencias nos acompañen, en algún momento, en la tarea de precisar los alcances y la importancia de una protección plena e integral del ser humano en todo lo que él significa y representa.

\section{b. El proyecto y los proyectos}

Cabe distinguir entre el "proyecto de vida", en singular, y los "proyectos de vida", en plural. Si bien el hombre vive proyectándose es dable distinguir entre los múltiples proyectos que el ser humano diseña en su vida, al menos uno de entre ellos que tiene la característica de su fundamentalidad para la existencia, que es radical, que compromete todo su ser, que es aquel en el que se juega su destino y el que otorga sentido a su vida. Nos referimos, en este caso, al "proyecto de vida" que es, por lo demás, el que nos interesa y al cual venimos refiriéndonos en el presente trabajo. Obviamente, es posible que al lado de este proyecto de vida pueda existir otro que también adquiere para el ser humano una especial trascendencia.

El daño al proyecto de vida acarrea como consecuencia un colapso psicosomático de tal magnitud para el sujeto -para cierto sujeto-que afecta su libertad, que lo frustra. El impacto psicosomático debe ser de una envergadura tal que el sujeto experimente un «vacío existencial». En esta situación, el ser humano se enfrenta a la nada al perder su vida su rumbo axiológico. Recogiendo una expresión de Milmaiene, «el desconsuelo invade a un hombre que pierde la fuente de gratificación y el cam-

\footnotetext{
50 Milmaikne, José E., "El daño psíquico" en Los nuevos daños, p. 71. Es conveniente aclarar, sin embargo, que el autor no distingue el daño al proyecto de vida, a pesar que lo describe con acierto, del daño psíquico al cual hace específica referencia.
} 
po de despliegue de su apuesta vital». Como el autor lo expresa con precisión, en el daño al proyecto de vida el impacto psicosomático es tan fuerte que ataca "el núcleo existencial del sujeto, sin el cual nada tiene sentido $"{ }^{50}$. El vacío existencial es el resultado de la pérdida de sentido que sufre la existencia humana como consecuencia de un daño a su proyecto de vida.

El daño al proyecto de vida, que bloquea la libertad, es la consecuencia de un daño psicosomático, ya que no es posible dañar «directamente» aquello de lo que se tiene «experiencia» pero que carece de «ubicación» en tanto se trata del ser mismo del hombre. Si el colapso es de una magnitud tal que sume al sujeto en un estado de pérdida de consciencia, que metafóricamente se suele describir y conocer como "vegetativo", es decir, de imposibilidad de comunicación, si bien no se aniquila la libertad en sí misma -lo que sólo sería posible con la muertese está, de hecho, anulando su capacidad de decisión. Si el daño, en cambio, es de un grado inferior en lo que se refiere a sus consecuencias, si bien no se anula la capacidad de decisión, se infiere al sujeto un daño que incide decisivamente en su posibilidad de "realizar» una decisión libre, de actuar un proyecto de vida. En este sentido, el daño al proyecto de vida compromete, seria y profundamente, la libertad del sujeto a ser "él mismo» y no "otro", afectándolo en aquello que hemos denominado su identidad dinámica, es decir, el despliegue de su personalidad ${ }^{51}$.

Al lado del mencionado "proyecto de vida", el ser humano está constantemente elaborando una pluralidad de proyectos sobre su cotidiano existir. Estos no comprometen el destino mismo del ser humano ni el sentido de su vida. Ellos carecen de la trascendencia del singular «proyecto de vida» en cuanto, de frustarse, no afectan el núcleo existencial del sujeto. En estas situaciones no se producen, por consiguiente, los devastadores efectos del daño al singular "proyecto de vida", los que sí truncan, de raíz, el periplo vital del sujeto. Sus consecuencias signan para siempre la vida de la persona. Los daños que pueden producir estas frustraciones ante decisiones libres que no comprometen el núcleo existencial del sujeto, pueden traducirse en consecuencias psíquicas de diversa medida y magnitud.

Es de advertir, por lo demás, que muchos proyectos que tienen que ver con la actividad cotidiana del sujeto, son repeticiones de alguno que en cierto momento fue original. Responden, por ello, a la habitualidad,

51 Fernández Shasarhio, Carlos, Derecho a la identidad personal, Astrea, Buenos Aircs, 1992, p. 113 y ss. 
por lo que el sujeto, muchas veces, no tiene conciencia de su libre decisión.

El daño al proyecto de vida, que tiene como causa u origen un daño psicosomático, bloquea, como apunta Milmaiene, «el logro de ansiadas metas u objetivos vitales, relacionados con fuertes ideales...». Lo que importa en este caso, como señala el autor, es «un hecho traumático en situación, relacionado con los valores, las metas y los ideales de un sujeto particular» ${ }^{52}$. Es decir, un daño que incide en el ámbito axiológico, que tiene como consecuencia una pérdida del sentido de la vida. En síntesis, se trata de lo que designamos como un daño al «proyecto de vida».

\section{c. Daño al proyecto de vida y daño psíquico}

Milmaiene no llega a distinguir, sin embargo, entre la lesión psicosomática, en sí misma, y aquella que, por su magnitud, puede originar en última instancia, en un caso límite, un daño al proyecto de vida. Es así que, a pesar de la exactitud de su descripción de las consecuencias que acarrea el daño a la persona no logra identificarlo como tal. En efecto, considera que existe una lesión psíquica que, en sus propias palabras, afecta «el núcleo existencial» mismo del sujeto. Es decir, se trata de un daño de tal magnitud que compromete no sólo la estructura psicosomática de la persona sino, como lo indica el propio autor, incide sobre el núcleo existencial. No se trata, por consiguiente, de una alteración o modificación patológica cualquiera del aparato psíquico. El daño a la persona es aquella lesión que trastoca el sentido existencial de la persona, que compromete su propio ser. En otros términos, lo que nosotros denominamos como «daño al proyecto de vida», resulta ser para Milmaiene tan sólo un daño psíquico de «la mayor importancia» o "un serio daño psíquico ${ }^{53}$.

El autor no parece haber percibido, a pesar de que su descripción de las consecuencias del daño al proyecto de vida son exactas, la diferencia de grado que existe entre el «daño psíquico», cualquiera sea su magnitud y que es siempre el antecedente del «daño al proyecto de vida», de este último. Las consecuencias que cada uno de tales daños generan en la vida del sujeto, tal como se advierte, son distintas. En un caso, como 
se ha subrayado, se produce tan sólo una alteración o modificación patológica del aparato psíquico, mientras que en el daño al proyecto de vida se trunca, de raíz, el sentido valioso de la vida.

En síntesis, no podemos confundir un daño a la estructura psicosomática del sujeto, que acarrea consecuencias biológicas -lesiones de todo tipo- y efectos en su salud -es decir, en el bienestar integral-, con el daño a la libertad misma del sujeto, el que se traduce en la frustración de su «proyecto de vida».

\section{d. Sintomatología del daño al proyecto de vida}

El daño al proyecto de vida, como está dicho, incide sobre la libertad del sujeto a realizarse según su propia libre decisión. Como lo hemos reiterado, es un daño de tal magnitud que afecta, por tanto, la manera en que el sujeto ha decidido vivir, que trunca el destino de la persona, que le hace perder el sentido mismo de su existencia. Es, por ello, un daño continuado, que generalmente acompaña al sujeto durante todo su existir en tanto compromete, de modo radical, su peculiar y única «manera de ser». No es una incapacidad, cualquiera, ni transitoria ni permanente, sino se trata de un daño cuyas consecuencias inciden sobre algo aún más importante para el sujeto como son sus propios fines vitales, los que le otorgan razón y sentido a su vida. El daño al proyecto de vida es un daño futuro y cierto, generalmente continuado o sucesivo, ya que sus consecuencias acompañan al sujeto, como está dicho, durante su transcurrir vital. Como anota De Cupis, el daño futuro es «aquel que si bien hasta entonces no ha nacido, es cierto que aparece en el futuro ${ }^{54}$. En este mismo sentido Zannoni considera que daño futuro «es aquel que todavía no ha existido, pero que ciertamente ha de existir, luego de la sentencia» ${ }^{55}$.

El daño futuro suele presentarse bajo dos modalidades. En una primera hipótesis se advierten consecuencias dañosas de un evento que ya ocurrió -es, decir, de un daño actual- , que no ha dejado de ponerse de manifiesto, de evidenciarse. De conformidad con el curso de los acontecimientos estas consecuencias se prolongarán en el tiempo, pudiendo aun agravarse. Se trata de un daño continuado o sucesivo.

54 D: Cupss, Adriano, El daño, Bosch, Barcelona, 1975, pp. 320 y 324,

55 Zannoni, Eduardo, Responsabilidad por daños, Astrea, Buenos Aires, 1882, p. 
En el segundo caso, el daño futuro no se presenta como la prolongación de un daño actual, sino que las consecuencias se han de evidenciar después de la sentencia judicial.

En ambas situaciones se trata de un daño futuro-cierto que debe ser reparado en tanto que su materialización sea verosímil, "que brinde una seguridad fundada en la razonable probabilidad objetiva de concretarse el perjuicio» ${ }^{56}$.

El daño al proyecto de vida no implica certeza, en sentido estricto. Pero, no cabe duda que por su importancia existencial, es previsible que, una vez producido, sus consecuencias se prolonguen en el tiempo según las circunstancias del caso y la experiencia de vida. Es obvio que la vida de un ser humano afectado en su libertad, en su núcleo existencial, no será la misma en el futuro. Corresponderá al juez, con fina sensibilidad, con una recreación valiosa del caso, percibir la existencia y magnitud del daño al proyecto de vida.

La frustración del proyecto de vida puede generar consecuencias devastadoras en tanto incide en el sentido mismo de la vida del ser humano, en aquello que lo hace vivir a plenitud, que colma sus sueños, sus aspiraciones, que es el correlato de ese llamado interior en que consiste la vocación personal. Cada ser humano vive «según» y «para» su proyecto existencial. Trata de realizarlo, de concretarlo, de convertirlo en una «manera de vivir», en su cardinal modo de existir.

Es esta la trascendencia, aún indebidamente valorada, que acarrea el daño al proyecto de vida. Sólo en tiempos recientes, por acción del personalismo, se ha logrado conocer mejor y, por ende, revalorizar al ser humano. Por ello, es que también sólo en estos tiempos sea posible empezar a comprender el tremendo significado que para la persona adquiere el daño al proyecto de vida. Seguir ignorándolo significaría desconocer, o aparentar desconocer, la compleja realidad del ser humano, en cuanto ser libre y temporal, a la que hemos aludido en precedencia y, por consiguiente, representaría una actitud tendente a empequeñecer el «valor de la vida humana».

\section{e. Consecuencias del daño al proyecto de vida}

Solemos utilizar un ejemplo, del cual hemos echado mano en otra opor-

so Stiglitz, Rubén y Stiglitz, Gabriel, Seguro contra la responsabilidad civil, Abeledo-Perrot, Buenos Aires, 1991, p. 233. 
tunidad, para explicar como es posible causar un daño al proyecto de vida. Es decir, a la expresión fenoménica de mi libertad hecha acto. Se trata del caso de un pianista por vocación, profesional, entregado por entero a su arte, cuya vida adquiere sentido vivenciando intensamente valores estéticos, cuya concreción se aprecia a través de la ejecución musical. Este pianista, a raíz de un accidente automovilístico, pierde algtlnos dedos de ambas manos.

Cualquier observador podrá comprobar que se ha producido un daño a un ser humano. Advierte también que este daño a la persona tiene múltiples consecuencias, unas personales o no patrimoniales y otras no personales o patrimoniales. Se trata, sin duda, de un grave infortunio. Por lo expuesto, podemos afirmar, sin ningún titubeo, que nos encontramos frente a un daño a la persona. El pianista no es una «cosa». Su peculiar naturaleza es la de ser un ser humano "pianista», libre y temporal.

Si analizamos los daños producidos en el caso del ejemplo propuesto encontramos, en primer lugar, que al pianista se le ha causado un evidente daño emergente que hay que indemnizar. La víctima ha sido internada en un centro hospitalario. Se deben, por consiguiente, cubrir los gastos derivados de su internamiento, los honorarios médicos, el costo de las medicinas empleadas, entre otras consecuencias. Pero, también, debe atenderse el lucro cesante, ya que el pianista acredita que tenía pendientes de ejecutar cinco conciertos, lo que supone una significativa suma de dinero que dejaría ciertamente de percibir. Estas serían algunas de las consecuencias patrimoniales o no personales del daño a la persona, fáciles de comprobar e indemnizar.

Pero, simultáneamente, el daño a la persona ha generado daños personales o no patrimoniales como es el caso del daño biológico, consistente en las lesiones causadas, consideradas en sí mismas y que serán valorizadas por los médicos legistas a la luz de los baremos o tablas de infortunios, si los hubiere, o atendiendo a la equidad, inspirada en la jurisprudencia. Se trata de lesiones físicas y, además, de alteraciones psíquicas. $Y$, al lado de este daño biológico, de carácter psicosomático, se ha producido un inevitable daño a la salud que compromete, en algún grado, el bienestar integral del sujeto, el mismo que debe también ser apreciado equitativamente por el juez a la luz de los informes de los médicos legistas.

Pero, además de los daños no patrimoniales antes referidos, se ha inferido a la persona un daño radical, que incide en el sentido mismo de su vida. Se ha frustrado su proyecto de vida, que consistía, única y exclusivamente, en «ser» pianista. El ser pianista otorgaba razón a su vida, 
sentido a su existencia, lo identificaba en la vida social a tal punto que cuando la gente lo ubicaba en un lugar público señalaba que se trataba de «un pianista».

No se puede reducir conceptualmente el daño al proyecto de vida con un daño a la estructura psicosomática del sujeto. Es obvio que para que exista un daño que incida en la libertad es necesario que se produzca, necesariamente, un daño biológico y un daño a la salud. Es decir, tenemos que hallarnos frente a lesiones o heridas producidas en el soma o cuerpo y en el aparato psíquico. Pero el daño al proyecto de vida, cuando aparece, trasciende este daño psicosomático para comprometer, como se ha insistido, el sentido mismo de la vida del sujeto. En el caso propuesto el daño biológico está dado por la lesión consistente en la pérdida de algunos dedos de la mano. Pero esta lesión, en el caso del pianista, compromete su futuro, le sustrae el sentido a su existencia, lo afecta en su núcleo existencial. Es decir, encontrarse en el futuro impedido de ser lo que era: «un pianista».

La pérdida de los dedos de la mano de un pianista o de un cirujano, la pérdida de las piernas de un deportista o un vendedor ambulante, o la desfiguración del rostro de un artista o de una modelo, no acarrea tan sólo un daño psicosomático. El daño reviste, en estos casos, una significación más profunda, una trascendental importancia. Como apunta Milmaiene, en estos casos «se anula todo proyecto de futuro», por lo que «nada de lo que se le propone como compensación puede restituir la autoestima herida», debida a la "pérdida de placer vital que genera el impedimento laboral, artístico o profesional $»^{57}$. No podemos olvidar que el trabajo, en cualquiera de sus múltiples manifestaciones, no sólo es el modo como el ser humano se inserta en la comunidad y presta un servicio, sino que, además, el trabajo libremente escogido supone su realización existencial.

¿Qué hará el pianista con su vida una vez que ella perdió su sentido? ¿Logrará superar tan enorme frustración? ¿Tendrá la fuerza suficiente, la necesaria y no común reserva moral, para encontrar una nueva razón para continuar viviendo? ¿Sucumbirá ante el devastador daño o, por el contrario, se sobrepondrá a su catástrofe personal? ¿Será capaz de llenar su vacío existencial, que es la mayor consecuencia de la frustración de su proyecto personal? Estas son algunas de las múltiples interrogantes que pucden formularse al contemplar el abatimiento existencial de un ser humano que se enfrenta a la frustración de su proyecto de vida generado 
por un daño a su persona. De una frustración que es de tal magnitud que le sustrae, nada menos, el sentido valioso de su vida.

Milmaiene se pregunta, con razón, frente al grave infortunio que significa el daño al proyecto de vida generado por la pérdida de los dedos de la mano para un cirujano o para un artista, sobre cuál puede ser el destino de un actor que no puede seguir actuando, o la de un cirujano que no puede continuar operando, cuando cada uno de ellos había encontrado en su práctica profesional un sentido para vivir, haciendo de ella una causa ${ }^{58}$. Es un caso en el cual, a partir de un daño psicosomático, el daño es más profundo, lo sobrepuja, ataca el núcleo existencial del ser humano, por lo que ya no se puede seguir refiriéndose a un daño psíquico, sino que, por su devastadora magnitud, por el colapso existencial que significa, debemos aludir a un daño al «proyecto de vida».

La frustración puede adquirir considerable magnitud, mientras que la reserva moral y humana del sujeto víctima del daño al proyecto de vida puede ser, por contraste, deficitaria, endeble, pobre. De ser así, la pérdida de los valores que daban sentido a su vida puede ocasionar un vacío existencial, de tales proporciones, que resulta imposible o difícil de llenar. Frente a este vacío existencial, enfrentado a la nada, el sujeto puede optar, en un caso límite, por el suicidio. Se trata de un drama existencial que no podemos soslayar.

En otra hipótesis, la víctima del daño al proyecto de vida puede buscar la manera de evadirse de una realidad que ya no le es propicia, en la que no ha estado acostumbrado a convivir, en la que ha perdido, en gran medida, su propia identidad, en la que ya no puede seguir vivenciando los valores que respondían a su personal vocación. Esta evasión podría conducir a la persona a refugiarse en alguna grave adicción, como serían las drogas o el alcohol. Ello significa el derrumbe de su personalidad, su degradación como persona.

Debe señalarse que la frustración del proyecto de vida del sujeto es siempre proporcional al interés e intensidad con que cada sujeto asume una posición existencial. Así, como acota Milmaiene, «para algunos todo lo que afecta el plano laboral puede ser determinante, así como para otros sólo cuentan los fracasos económicos, o bien para terceros lo esencial es la preservación de la integridad del plano afectivo ${ }^{59}$.

En la mejor de las hipótesis, las consecuencias del daño al proyecto de vida lograrán sobrellevarse de algún modo si el sujeto tiene otros va- 
lores, de parecida, igual o mayor importancia, cuya vivencia le otorguen a su vida un nuevo sentido, que podría, de alguna manera, sustituir al que parecía haber perdido. Podría ser el caso de un ser humano de extraordinaria fortaleza moral, de coraje, de un impresionante deseo de vivir, de una honda vocación de servicio a los demás. Tal vez en el servicio al prójimo, si el sujeto es solidario, podría, de superar su trauma existencial, encontrar la nueva razón de su vida.

No puede descartarse, sin embargo, el que existan situaciones en las que se atenúan y hasta casi pueden no presentarse consecuencias de magnitud en lo que concierne a un daño al proyecto de vida. Nos referimos a casos en los cuales las personas carecen de un proyecto de vida suficientemente definido, bien delineado, vigoroso. Es decir, de un proyecto que no emerge de decisiones firmes, de profundas convicciones personales, de intensas vocaciones. Se trataría, en esta hipótesis, de un sujeto desorientado, inseguro, que no posee un proyecto marcado por una connotación personal, de perfiles poco nítidos, donde no se advierten con claridad los valores que el sujeto ha decidido vivenciar y que, de hecho, vivencia.

En el caso mencionado en el párrafo anterior estamos frente a un sujeto que no vivencia, con intensidad y convicción, casi con pasión, un determinado proyecto de vida. Ello no significa, en última instancia que el sujeto carezca en absoluto de un proyecto de vida, ya que ello no sería posible dada su naturaleza de ser libre y temporal. Se trataría de personas vocacionalmente desorientadas, que no perciben con nitidez sus propios fines por lo que no se han propuesto un definido proyecto de vida. El proyecto puede aparecer incierto, cambiante, carente de fuerza vital. Es evidente que en estas particulares circunstancias, que generalmente son fácilmente perceptibles por el juez $\mathrm{y}$, con mayor razón, por los expertos, las consecuencias derivadas del daño al proyecto de vida son irrelevantes o de escasa magnitud.

Podemos asistir a otra situación en la que el sujeto tiene un proyecto de vida, libremente elegido, pero que no ha sido capaz o no ha podido realizarlo. El proyecto existe, pero no se ha cumplido. Quedó a nivel de decisión. En esta hipótesis no podríamos referimos válidamente a la presencia de un daño al proyecto de vida en la medida que él no es visible, que no se ha convertido en actividades cotidianas del sujeto. Sin embargo, cabe argumentar que esta persona puede intentar, nuevamente, llevar adelante su proyecto de vida, por lo que el daño producido trunca cualquier expectativa de futura realización personal. Es decir, que si bien no existe un proyecto en plena realización, nos hallamos ante una incumplida libre decisión personal, pero abierta al futuro. 
Es dable plantear un hecho que frecuentemente no resulta suficientemente claro. Nos referimos al caso de las incapacidades permanentes de carácter somático, las mismas que no siempre y necesariamente traen como consecuencia la frustración del proyecto de vida, sino sólo acarrean ostensibles y perjudiciales limitaciones en relación con otras actividades que no corresponden o no afectan el núcleo de su proyecto de vida. Podría ser el caso de un pianista que pierde alguna parte o función de su cuerpo, lo que no le impide continuar con su proyecto existencial no obstante causarle serias y graves limitaciones en la realización normal de su vida.

Somos conscientes de las dificultades por las que podría atravesar el juez para determinar la magnitud de un daño al proyecto de vida de la persona, de cada persona en particular, así como las que se presentan en el momento de fijar una adecuada reparación. Este constituye probablemente un problema imposible de resolver con exactitud matemática, situación que se agrava dadas tanto las características propias de cada ser humano como la importancia que para él comporta su proyecto de vida. Sin embargo, la indudable existencia de estas dificultades no pueden conducir a soslayar o a ignorar la importancia y las graves repercusiones que genera el daño al proyecto de vida y a negar, por consiguiente, su reparación.

Por el contrario, conscientes del valor de la vida humana y de su connatural dignidad estimamos que, cuando sea posible y evidente, se repare de modo equitativo, de acuerdo a las circunstancias y frente al caso concreto, las consecuencias del daño al proyecto de vida. Las dificultades para su reparación, que pueden presentarse ya sea en el diagnóstico de la existencia de un daño a la persona o a través de los obstáculos que pueden surgir cuando se pretende precisar sus alcances y consecuencias en la vida de un determinado ser humano, no pueden justificar, en ningún caso, que la víctima no reciba la equitativa reparación por el daño realmente sufrido. Ello, en última instancia, depende de la sensibilidad y preparación del juez para captar, con la finura de análisis que se requiere, este específico daño y sus consecuencias en cada uno de los casos que sean sometidos a su conocimiento.

En síntesis, para la apreciación del daño y sus consecuencias tanto en el caso del daño al proyecto de vida como también en el daño psíquico, «las generalizaciones o universalizaciones no tienen cabida, dado que un hecho que puede resultar catastrófico para una persona, no tiene ningún valor para otra y viceversa ${ }^{60}$. Esta situación corrobora la particular dig- 
nidad del ser humano, que se sustenta en que cada uno, por ser libre, tiene una propia identidad, lo que hace que sobre una base de igualdad del género humano, cada persona esté dotada de una especial personalidad, de una particular sensibilidad para vivenciar valores. El ser humano es único, singular, irrepetible, no estandarizado, impredecible, dinámico, histórico. Todas estas connotaciones obligan al juez, dejando de lado las técnicas para la apreciación y cuantificación de los daños patrimoniales, tratar cada caso de daño al proyecto de vida como "el caso» y no como "un caso más». Esta característica del ser humano complica la apreciación y las consecuencias del daño al proyecto de vida.

\section{f.- Daño al proyecto de vida y daño moral}

Por todo lo expuesto, no es posible confundir el llamado «daño moral» que, como lo hemos expresado, incide sobre la esfera afectiva del sujeto, del trascendente "daño al proyecto de vida» que afecta el sentido mismo de la existencia, tal como lo hemos intentado describir en precedencia.

Las consecuencias del daño moral, que hieren los sentimientos y los afectos de la persona, por hondas que puedan ser, no suelen acompañar al sujeto, al menos con la intensidad inicial, durante su transcurrir vital. La tendencia general es que dichas consecuencias, los dolores o sufrimientos, suelen disiparse, disminuir o atenuarse con el pasar del tiempo. Así, un profundo y explicable dolor experimentado por la muerte de un ser querido es muy intenso en un primer momento pero, poco a poco, va diluyéndose, transformándose en otros sentimientos y afectos. Muchas veces el dolor inicial se convierte, con el transcurso del tiempo, en un sentimiento duradero de orgullo por la calidad humana del que ya no nos acompaña en la ruta de la vida, o en uno de gratitud para con el ser querido que dejó de existir por lo mucho que de él recibimos mientras estuvo con nosotros. Más que con dolor, muchas veces evocamos con ternura, nostalgia y afecto la memoria de quien nos abandonó. Con frecuencia, el sufrimiento que experimentamos cn el pasado se transforma en una remembranza de sus cualidades personales y, al considerarlo como un paradigma, tratamos de seguir su ejemplo.

En cambio, en el supuesto del daño al proyecto de vida la situación es diferente. Se trata de un daño cuyas consecuencias, que comprometen la existencia misma del sujeto, suelen perdurar. Ellas difícilmente logran ser superadas con el transcurso del tiempo. El daño causado es de tal magnitud que frecuentemente acompañan a la persona por toda la vida, por lo que compromete su futuro. La víctima ha perdido, en gran medida, su 
propia identidad. Dejó de ser lo que libremente se propuso ser. Dejó de realizarse a plenitud. Es, pues, imposible confundir las consecuencias, a menudo devastadoras del daño al proyecto de vida, con aquellas otras, de naturaleza afectiva, que son constitutivas del daño moral.

\section{Protección jurídica del proyecto de vida}

Como muy bien se prescribe en el artículo 1549 del Proyecto de Reforma del Código Civil argentino, formulado por la Comisión designada por el Poder Ejecutivo, «la violación del deber de no dañar» genera la obligación de reparar el daño causado conforme a las disposiciones del Código. Constituye, a nuestro entender, un acierto legislativo recordar que todo ser humano no sólo posee derechos, como supone el individualismo exacerbado, sino que tiene, aparte de una infinitud de deberes que derivan de cada uno de sus derechos, un deber genérico consistente en «no dañar». Bastaría este simple enunciado para que, a partir de él, los jueces tutelaran cualquier tipo de daños que pudiera sufrir el sujeto en su persona o en sus bienes o en los de la comunidad. El deber de no dañar, por lo demás, da cuenta de la dimensión coexistencial o intersubjetiva del Derecho.

El principio de non laedere cubre, por consiguiente al ser humano entendido como una unidad existencial y lo protege, por ende, de modo integral y preventivo. No es necesario mencionar o inventariar o hacer un catálogo de todos los múltiples derechos e intereses del ser humano que merecen específica tutela jurídica. Como algunos autores sostienen fundándose en esta realidad, existe un sólo derecho de la persona que se sustenta en su propia dignidad de ser libre y temporal y en el consiguiente deber de los demás de respetar esta peculiar condición.

Esta posición va adquiriendo paulatina importancia en nuestros días, ya que se tiende a variar los tradicionales alcances del «derecho subjetivo" a fin de sustraerle toda connotación absolutista. Ello ha dado lugar, atendiendo a la realidad del sujeto como un ente libre pero al mismo ticmpo coexistencial, que todo derecho supone un correlativo deber y que, a su vez, todo deber conlleva un derecho. Es decir, se ha logrado superar el concepto tradicional de derecho subjetivo sustituyéndolo por el de «situación jurídica subjetiva», el mismo que denota esta nueva noción de amplios alcances ${ }^{61}$. La «situación jurídica subjetiva» da cuenta de la realidad coexistencial del Derecho.

61 Frrnajndz Stessarbigo, Carlos, Abuso del derecho, Astrea, Buenos Aires, 1992, pp. 54 y ss. 
Pero, además y como es lógico, las modernas constituciones y ciertos códigos civiles incluyen normas que protegen la libertad del ser humano o su «libre desarrollo» o el «libre desenvolvimiento de su personalidad».

Así, la Constitución Política del Perú de 1993 prescribe en el inciso 1 de su artículo $2^{\circ}$ que toda persona tiene derecho a «su libre desarrollo». Es decir, se tutela la actuación fenoménica de la libertad, cuya máxima expresión, que duda cabe, es el singular "proyecto de vida". Este derecho encuentra también su amparo en el Código Civil de 1984, en el cual el artículo $5^{\circ}$ tutela expresamente "la libertad» del ser humano. Es decir, la libertad que sustenta su actuación proyectiva.

Por su parte, el artículo $2^{\circ}$ de la Constitución italiana de 1947 protege «los derechos inviolables del hombre», mientras que la Constitución española de 1978 es más explícita cuando, en su artículo $10^{\circ}$, considera que «la dignidad de la persona, los derechos inviolables que le son inherentes, el libre desarrollo de la personalidad, el respeto a la ley y a los derechos de los demás son fundamento del orden político y de la paz social».

El artículo $5^{\circ}$ de la Constitución colombiana de 1991 establece que «el Estado reconoce, sin discriminación alguna, la primacía de los derechos inalienables de la persona»y, en su artículo $16^{\circ}$, prescribe que «todas las personas tienen derecho al libre desarrollo de su personalidad sin más limitaciones que las que imponen los derechos de los demás y el orden jurídico".

Como se desprende de los casos emblemáticos antes citados los ordenamientos jurídicos protegen genéricamente los derechos inviolables del hombre, inherentes a su propio ser o, expresamente, tutelan la libertad o su libre desarrollo o el libre desenvolvimiento de la personalidad. Es decir, bajo diversas fórmulas, se protege la libertad, en sí misma, y su actuación o expresión fenoménica, cuyo máximo exponente es el proyecto de vida.

\section{Corolario}

$\mathrm{Al}$ concluir esta propuesta, este manojo de reflexiones y sugerencias que fluyen de la observación de la vida misma y de nuestra experiencia existencial, desearíamos reafirmar, una vez más, que todo ello ha sido posible a partir de los hallazgos y aportes del personalismo jurídico que, en tiempos recientes, ha reivindicado para el derecho el valor de la vida humana. De igual manera, quisiéramos recordar, con Busnelli, que la laboriosa y controvertida elaboración de una noción comprensiva del 
daño a la persona, que incluye los matices que hemos señalado y que resultan de la compleja y rica estructura psicosomática del ser humano, tiene un profundo significado en la medida que representa una triple conquista del derecho contemporáneo ${ }^{62}$.

La primera de ellas, de enorme trascendencia, es el que tanto la doctrina como la jurisprudencia comparadas han abandonado en la última década el criterio que tenía exclusivamente en consideración el aspecto económico de la vida humana para los efectos de la reparación del daño a la persona. Esta miope actitud había arrastrado al derecho a un tratamiento decididamente materialista de la vida humana. Haber superado esta posición resulta ser una evidente conquista. Se ha dejado atrás la concepción del homo faber, del hombre productor de renta, para sustituirla por otra en la que el ser humano, cualquier ser humano, al tener pareja dignidad, merece, por consiguiente, la plena protección del Derecho.

No podrá seguir considerándose en el futuro que existen seres humanos de primera categoría, privilegiados sólo por producir riqueza, con menoscabo de aquellos otros, tenidos como de segunda categoría, por cl simple hecho que, por circunstancias generalmente ajenas a su voluntad, no cumplían este específico rol social. No es posible que, bajo un estrecho criterio economicista, se marginase y se desamparase a los niños, a los ancianos, a los desocupados, a las amas de casa, a los incapacitados. Según esta óptica materialista no cabía reparar los daños que se causasen a estos sujetos, tenidos como verdaderos parias del derecho.

Una segunda conquista, al decir del propio Busnelli, es aquella de haber logrado diseñar una noción de daño a la persona, lo suficientemente amplia, que pueda cubrir una infinidad de posibles daños y obtener su casi general reconocimiento jurisprudencial y doctrinario, lo que no ha sido nada fácil si se tiene en cuenta la evolución conceptual del daño a la persona. Conquista que ha llegado a plasmarse, inclusive, en algún código civil contemporáneo, nativo de nuestro subcontinente latinoamericano, donde se acoge el deber de reparar el daño a la persona sin limitación alguna.

Finalmente, una tercera conquista es la de haber comprometido en el estudio y diseño del daño a la persona y de su consiguiente reparación no sólo a juristas sino a médicos legistas, economistas, psicólogos, aseguradores, expertos en cálculos actuariales, entre otros. Es decir, en el 
análisis del daño la persona ha convocado a equipos interdisciplinarios, lo que permite un mejor, más amplio y más fino tratamiento del tema que nos preocupa.

No está dicha, aún, la última palabra en lo que concierne al daño a la persona $y$, en especial, en lo que atañe al novísimo daño al proyecto de vida. De otro lado, no se ha esclarecido aún, de modo definitivo, para un sector de la doctrina, los linderos conceptuales entre el genérico daño a la persona y el específico daño moral. Se requiere todavía de un período de sedimentación de las ideas expuestas, de su debida cvaluación.

Todo lo expuesto nos permite comprobar que todavía nos hallamos inmersos en un proceso de afinamiento y profundización constante de dichas nociones, sobre todo en lo que se refiere a la debida valorización y liquidación del daño a la persona en cualquiera de sus aspectos. Demostrativo de este proceso es, sin duda, el importante desarrollo que se observa, en cuanto al daño a la persona, en los más recientes pronunciamientos judiciales, así como los numerosos congresos internacionales que se ocupan del tema y la cada vez más abundante literatura jurídica que enriquece nuestro conocimiento de la materia. Se ha logrado, así, un relativo avance como es el de sensibilizar a los hombres de derecho en torno a la gravitación jurídica del daño a la persona y, en especial, del daño al proyecto de vida, así como sobre la exigencia en cuanto a su justa reparación. Resta, sin embargo, que un todavía significativo sector de la doctrina logre compenetrarse con estos nuevos planteamientos de inspiración humanista. Estamos convencidos que ello sucederá en los próximos años como natural producto de la madura reflexión de las ideas propuestas por el personalismo jurídico. En esta dirección, no obstante los múltiples tropiezos que se advierten, se mueve la historia. 